\title{
Spontaneous Bursting Activity in the Developing Entorhinal Cortex
}

\author{
Maxim G. Sheroziya, ${ }^{1,2}$ Oliver von Bohlen und Halbach, ${ }^{1,3}$ Klaus Unsicker, ${ }^{1,4}$ and Alexei V. Egorov ${ }^{1,2,4}$ \\ ${ }^{1}$ Interdisciplinary Center for Neurosciences, Department of Neuroanatomy, University of Heidelberg, D-69120 Heidelberg, Germany, ${ }^{2}$ Institute of Higher \\ Nervous Activity and Neurophysiology, Russian Academy of Sciences, 117485 Moscow, Russia, ${ }^{3}$ Institute of Anatomy and Cell Biology, University of \\ Greifswald, D-17487 Greifswald, Germany, and ${ }^{4}$ Department of Molecular Embryology, Institute of Anatomy and Cell Biology, University of Freiburg, \\ D-79104 Freiburg, Germany
}

Periodic spontaneous activity represents an important attribute of the developing nervous system. The entorhinal cortex (EC) is a crucial component of the medial temporal lobe memory system. Yet, little is known about spontaneous activity in the immature EC. Here, we investigated spontaneous field potential ( $\mathrm{fp}$ ) activity and intrinsic firing patterns of medial EC layer III principal neurons in brain slices obtained from rats at the first two postnatal weeks. A fraction of immature layer III neurons spontaneously generated prolonged (2-20 s) voltage-dependent intrinsic bursting activity. Prolonged bursts were dependent on the extracellular concentration of $\mathrm{Ca}^{2+}\left(\left[\mathrm{Ca}^{2+}\right]_{\mathrm{o}}\right)$. Thus, reduction of $\left[\mathrm{Ca}^{2+}\right]_{o}$ increased the fraction of neurons with prolonged bursting by inducing intrinsic bursts in regularly firing neurons. In $1 \mathrm{mM}\left[\mathrm{Ca}^{2+}\right]_{0}$, the percentages of neurons showing prolonged bursts were $53 \%, 81 \%$, and $29 \%$ at postnatal day 5 (P5)-P7, P8-P10, and P11-P13, respectively. Prolonged intrinsic bursting activity was blocked by buffering intracellular Ca ${ }^{2+}$ with BAPTA, and by $\mathrm{Cd}^{2+}$, flufenamic acid (FFA), or TTX, and was suppressed by nifedipine and riluzole, suggesting that the $\mathrm{Ca}^{2+}$-sensitive nonspecific cationic current $\left(I_{\text {CAN }}\right)$ and the persistent $\mathrm{Na}^{+}$current $\left(I_{\mathrm{Nap}}\right)$ underlie this effect. Indeed, a $0.2-1$ s suprathreshold current step stimulus elicited a terminated plateau potential in these neurons. fp recordings at P5-P7 showed periodic spontaneous glutamate receptormediated events ( sharp fp events or prolonged fp bursts) which were blocked by FFA. Slow-wave network oscillations become a dominant pattern at P11-P13. We conclude that prolonged intrinsic bursting activity is a characteristic feature of developing medial EC layer III neurons that might be involved in neuronal and network maturation.

\section{Introduction}

Periodic spontaneous activity is a characteristic feature of the developing nervous system. It is believed that early spontaneous activity is involved in the modulation of several processes during brain maturation, including neuronal growth, synapse formation, and network construction (Ben-Ari, 2002). Initially described in the hippocampus using intracellular recordings and termed giant depolarizing potentials (GDPs) (Ben-Ari et al., 1989), the periodic spontaneous network events have also been observed in a wide range of developing brain structures, including cortex, spinal cord, and retina (O’Donovan, 1999; Feller, 1999; Garaschuk et al., 2000). Despite basic similarity of the phenomena, the patterns of synchronous activity as well as the mechanisms underlying spontaneous events might be highly diverse depending on the brain structure and developmental stage (Feller et al., 1996; Leinekugel et al., 1997; Kandler and Katz, 1998; Dupont et al., 2006; Crépel et al., 2007; Allène et al., 2008). In the

Received March 19, 2009; revised Aug. 11, 2009; accepted Aug. 17, 2009.

This work was funded by the Deutsche Forschungsgemeinschaft (SFB 636/A5, SFB 488/D13) and in part by the Russian Foundation for Basic Research. We thank Andreas Draguhn (Heidelberg) for fruitful discussions and helpful comments on this manuscript. We also thank Pavel M. Balaban (Moscow) for his strong support of this work.

Correspondence should be addressed to Dr. Alexei V. Egorov, Interdisciplinary Center for Neurosciences, Department of Neuroanatomy, University of Heidelberg, Im Neuenheimer Feld 307, D-69120 Heidelberg, Germany. E-mail: alexei.egorov@urz.uni-heidelberg.de.

DOI:10.1523/JNEUROSCI.1333-09.2009

Copyright $\odot 2009$ Society for Neuroscience 0270-6474/09/2912131-14\$15.00/0 immature cortex, spontaneous electrical activity and large-scale oscillatory calcium waves have been observed both in vitro and in vivo (Yuste et al., 1992; Garaschuk et al., 2000, Corlew et al., 2004; Khazipov et al., 2004; Adelsberger et al., 2005; Hanganu et al., 2006; Khazipov and Luhmann, 2006). Recently, four distinct patterns of early spontaneous activity, differing by their developmental profile, calcium dynamics, and mechanisms, were defined in the immature cortex: uncorrelated calcium spikes, cortical synchronous plateau assemblies (cSPAs) nesting recurrent bursts via gap junction coupling, glutamate-driven cortical early network oscillations (cENOs) (Garaschuk et al., 2000), and a cortical pattern corresponding to GABA-driven GDPs (cGDPs) (Allène et al., 2008).

It is generally accepted that the early excitatory actions of GABA have a central role in the generation of GDPs (Ben-Ari et al., 2007), whereas cENOs are generated by activation of glutamatergic synapses mostly through NMDA receptors (NMDARs) (Allène et al., 2008). However, the hypothesis that the mechanism of rhythmogenesis for early network oscillations could involve the activity of cell autonomous pacemakers in a recurrent synaptic network is under investigation. Recently, it has been shown that intrinsic bursting of immature starburst cells underlies the generation of retinal waves (Zheng et al., 2006). Moreover, neurons displaying intrinsic rhythmic activity were described in the developing hippocampus (Sipilä et al., 2005, Crépel et al., 2007). 
However, the existence of pacemakers driving early network patterns in developing central structures is still unclear.

The entorhinal cortex (EC) is a crucial component of the medial temporal lobe memory system (Squire et al., 2004). The EC constitutes the major interface between the hippocampus and the parahippocampal cortex and is subdivided into a medial area (mEC) and a lateral area (IEC). The EC exhibits complex extrinsic and intrinsic connections (for review, see van Strien et al., 2009). Thus, early spontaneous activity in the EC might be involved in functional and structural development of hippocampal and cortical networks. Yet, little is known about early spontaneous activity within the EC. Here, we investigated spontaneous activity in layer III (LIII) of the immature $\mathrm{mEC}$ by using whole-cell, cellattached, and field potential (fp) recordings in horizontal brain slices.

\section{Materials and Methods}

Preparation of brain slices. Horizontal brain slices (500-600 $\mu \mathrm{m}$ thick) containing the hippocampus and entorhinal and parts of perirhinal cortices were obtained from Wistar rats at the first two postnatal weeks [postnatal day 1 (P1)-P13] by using standard procedures. P0 was taken as the day of birth. All experimental protocols were performed in accordance with the National Institutes of Health Guide for the Care and Use of Laboratory Animals and were approved by the state government of BadenWürttemberg. Animals were decapitated, and brains were rapidly removed and placed in a cold $\left(4-6^{\circ} \mathrm{C}\right)$ oxygenated artificial CSF (ACSF) containing (in mM): $124 \mathrm{NaCl}, 3 \mathrm{KCl}$, 1.6 $\mathrm{CaCl}_{2}, 1.8 \mathrm{MgSO}_{4}, 26 \mathrm{NaHCO}_{3}, 1.25$ $\mathrm{NaH}_{2} \mathrm{PO}_{4}$, and 10 glucose (for interface recording) or containing $130 \mathrm{NaCl}, 3.5 \mathrm{KCl}, 1.2$ $\mathrm{NaH}_{2} \mathrm{PO}_{4}, 25 \mathrm{NaHCO}_{3}, 1.3 \mathrm{MgCl}_{2}, 1$ or 2 $\mathrm{CaCl}_{2}$, and 25 glucose (for submersion-type recording). Then, brains were saturated with $95 \% \mathrm{O}_{2}$ and $5 \% \mathrm{CO}_{2}, \mathrm{pH}$ 7.4. Brain slices were cut using a manual Vibratome slicer (Campden Instruments) and were then incubated in a holding chamber for at least $1 \mathrm{~h}$ at room temperature. Individual slices were transferred into a recording chamber one by one, superfused with ACSF at a rate of $1-3 \mathrm{ml} / \mathrm{min}$, and maintained at $33 \pm 1^{\circ} \mathrm{C}$. For extracellular fp recordings, slices were allowed to recover in a recording chamber for at least $1 \mathrm{~h}$ before starting a recording session.

Recording procedures. Whole-cell patch-clamp recordings were made under visual guidance using an Olympus microscope fitted with infrared differential interference contrast optics (Olympus BX51WI). The lamina dissecans (sometimes referred to as layer IV) was used as a reference of the deep border of LIII. Pyramidal neurons located in deeper part of LIII were preferentially recorded. Current-clamp recordings were performed with an Axopatch 1D patch-clamp amplifier (Axon Instruments) in a submersion-type recording chamber. Patch electrodes were backfilled with the following (in mM): $115 \mathrm{~K}$-gluconate, $20 \mathrm{KCl}$, 10 disodium phosphocreatine, 10 HEPES, 4 MgATP, and 0.3 GTP (tip resistance of 10-12

A

B

C a

D

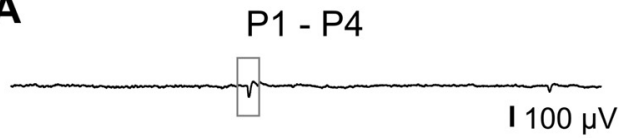
P5 - P7
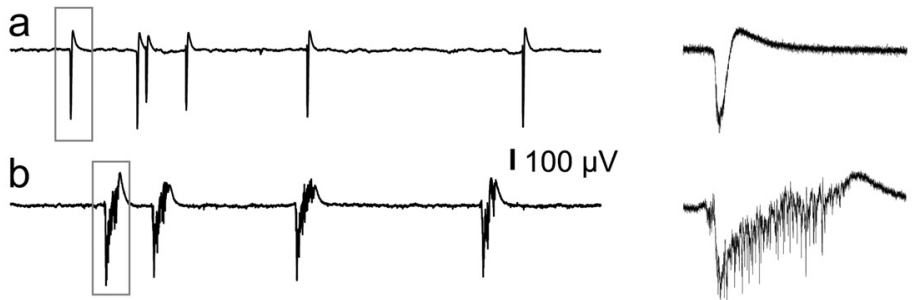

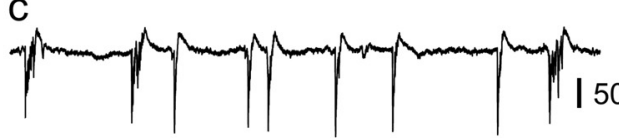
P8 - P10
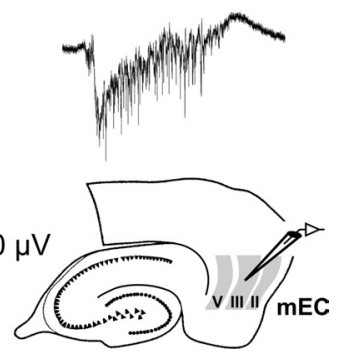

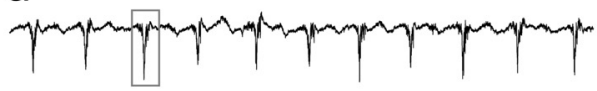

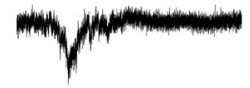

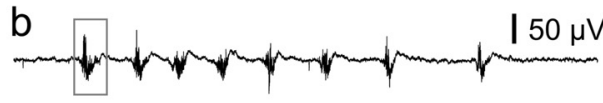

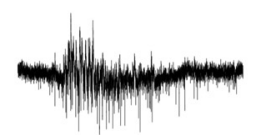

Figure 1. Periodic spontaneous field activity in the developing $\mathrm{mEC}$. Characteristic spontaneous fp activity in the $\mathrm{mEC}$ LIII recorded in slices at P1-P4 (A), P5-P7 (B), P8 -P10 (C), and P11-P13 (D) (low-pass filter at $25 \mathrm{~Hz})$. Right, Events marked on the left are shown at an expanded time scale (raw data). $\boldsymbol{A}$, Individual fp events accompanied with unit discharges detected in a P2 slice. $\boldsymbol{B}$, Periodic spontaneous fp activity recorded at P5-P7 is characterized by a selective presence of sharp fp events ( $\boldsymbol{a}$, trace at P5), prolonged fp events accompanied by fp fluctuations ("fp bursts") (b, trace at P7), or of both forms simultaneously (c, trace at P6). $B C$, Right, Schematic representation of the horizontal hippocampal-EC slice with the position of recording electrode. $C$, Periodic fp events recorded at P8 -P10. Note the increase of network rhythmicity for sharp fp events (a, P10) and fp bursts ( $\boldsymbol{b}$, P8). D, Typical spontaneous slow-wave network activity at P11-P13 (specimen trace at P11). $E$, Bar diagrams summarizing the mean durations and peaks of amplitude of $\mathrm{fp}$ events at four sequential postnatal periods. Error bars indicate SD. ${ }^{*} p<0.05,{ }^{* * *} p<0.005$.

$\mathrm{M} \Omega$ ). The electrode solutions were adjusted to $\mathrm{pH} 7.2$ with $1 \mathrm{~m} \mathrm{KOH}$. Data were low-pass filtered at $1 \mathrm{kHz}$, digitized at $5-10 \mathrm{kHz}$, and stored on a personal computer using the LTP230 software package (courtesy of W. W. Anderson, Bristol University, Bristol, UK) (Anderson and Collingridge, 2001). Extracellular fp recordings were performed with an Axoclamp-2B amplifier (Axon Instruments) and a DPA-2FX extracellular amplifier (NPI Electronics) in an interface recording chamber (Fine Science Tools). Signals were filtered on-line at $1 \mathrm{kHz}$ and digitized at $5-10 \mathrm{kHz}$ by an analog to digital converter 1401 MICRO [Cambridge Electronic Design (CED)]. Extracellular signals were stored on a computer using Spike2 software (CED). fp recordings were obtained with 
ACSF-filled glass capillary electrodes (tip resistance of $\sim 1 \mathrm{M} \Omega$ ) placed in LIII of the mEC. The EC was identified with a dissecting microscope by transillumination. An extracellular bipolar electrode (SNEX-200, Rhodes Medical Instruments) was used to induce synaptic fp responses by local stimulation of the lEC. Pulses $(0.1 \mathrm{~ms}, 5-25 \mathrm{~V})$ were delivered with an Iso-Flex stimulus isolator (AMPI) triggered by a Master-8 VP pulse generator. Parts of stimulation artifacts were eliminated in the represented traces. Experiments on the "isolated EC" (isol-EC) were performed on slices containing both lateral and medial parts of the EC.

Chemicals. Flufenamic acid (FFA, 10, 20, $50 \mu \mathrm{M})$, riluzole $(5,10 \mu \mathrm{M})$, nifedipine $(10,50,100 \mu \mathrm{M})$, mefloquine $(25,50 \mu \mathrm{M})$, tetraethylammonium chloride (TEA, $1 \mathrm{mM}$ ), tetrodotoxin (TTX, $1 \mu \mathrm{M}$ ), atropine $(10 \mu \mathrm{M})$ (all from Sigma-Aldrich), and $\mathrm{CdCl}_{2}(100 \mu \mathrm{M}), \mathrm{NiCl}(100 \mu \mathrm{M})$, and E4CPG (200 $\mu \mathrm{M}$, Tocris Cookson) were bath applied by continuous perfusion. FFA and riluzole were applied from stock solutions made in DMSO. The final concentration of DMSO in ACSF was $\leq 0.1 \%$. Control experiments revealed no measurable effects of DMSO on cellular properties or network periodic events $(n=5)$. 1,2-Bis(2aminophenoxy)ethane- $N, N, N^{\prime}, N^{\prime}$-tetra-acetic acid (BAPTA, $30 \mathrm{~mm}$, Sigma-Aldrich) was applied intracellularly through the patch pipette solution for 10-20 min. BAPTA solution (30 mM) contained the following (in $\mathrm{mm}$ ): $30 \mathrm{~K}_{4}$-BAPTA, 50 sucrose, $20 \mathrm{KCl}, 10$ disodium phosphocreatine, 10 HEPES, 4 MgATP, and 0.3 GTP. The solutions were adjusted to $\mathrm{pH} 7.2$ with $1 \mathrm{M} \mathrm{KOH}$. Blockade of ionotropic glutamate receptor (iGluR) and $\mathrm{GABA}_{\mathrm{A}}$ receptor $\left(\mathrm{GABA}_{\mathrm{A}} \mathrm{R}\right)$-mediated neurotransmission was performed with a drug mixture consisting of either a mixture of kynurenic acid ( $2 \mathrm{~mm})$ and picrotoxin $(100 \mu \mathrm{M})$ or a mixture of DL-2-amino-5-phosphonovaleric acid (APV, $60 \mu \mathrm{M}$ ), 6-cyano-7-nitroquinoxaline-2,3-dione (CNQX, $30 \mu \mathrm{M}$ ), and picrotoxin (100 $\mu \mathrm{M}$, all from Sigma-Aldrich, Taufkirchen, Germany). To investigate the role of GABAergic transmission in generation of fp activity, we applied picrotoxin $(20 \mu \mathrm{M})$ in the bath for $10 \mathrm{~min}$, and then the drug was washed out for $\sim 60 \mathrm{~min}$. In our experiments, the slices were superfused with ACSF containing 2, 1.6 , or $1 \mathrm{mM} \mathrm{Ca}^{2+}\left(\left[\mathrm{Ca}^{2+}\right]_{0}\right)$, which in bicarbonate-based solution corresponds in fact to lower values. Thus, by using $1.6 \mathrm{~mm}\left[\mathrm{Ca}^{2+}\right]_{\mathrm{o}}$ the real free extracellular $\mathrm{Ca}^{2+}$ concentration in bicarbonate-based ACSF is $\sim 1.2 \mathrm{~mm}$ (Yue et al., 2005).

Data analysis. Electrophysiological data were analyzed off-line using Spike2 software (CED). fp activity at P1-P4 was analyzed from 10 min recordings in each of 40 slices ( 10 slices from four rats for each postnatal day). fp activity at P5-P7 was analyzed from at least 5 min of primary data. Duration of fp events (DE) was measured from the onset of negativity until the peak of positivity before the field waveform return to the baseline level. The peak amplitude of fp events (PA) was calculated as the difference from baseline to peak of the field waveform. The preferred frequency of events (pFE) was calculated as a peak in the distribution of interevent intervals. In illustrations, field potential recordings were lowpass filtered at $25 \mathrm{~Hz}$. Effect of lowering $\left[\mathrm{Ca}^{2+}\right]_{o}$ on fp events was analyzed from 5 min of recordings (control vs 20-30 min perfusion of ACSF containing $1 \mathrm{mM} \mathrm{Ca}^{2+}$ ). fp activity at $\mathrm{P} 8-\mathrm{P} 13$ was calculated from $1 \mathrm{~min}$ recordings. Spontaneous paroxysmal field discharges elicited by picrotoxin were calculated from $1 \mathrm{~min}$ recordings at a period with the maximal amplitude of discharges. "Amplitude" of discharges and seizure-like events was defined as the difference between the most negative and most positive data points during an event, and duration was measured from the onset of negativity until the peak of positivity before the fp return to the baseline. Spontaneous intrinsic firing activity was analyzed from at least $2 \mathrm{~min}$ of recordings. Bursting activity in the presence of $100 \mu \mathrm{M}$ nifedipine was recorded and analyzed after depolarization of membrane potential to $-52 \pm 3 \mathrm{mV}$ versus $-60 \pm 1.2 \mathrm{mV}$ in control recordings. Burst duration was calculated as the time between the first spike of a burst and the last spike of that burst. Interburst interval was defined as the point from the end of a burst to the beginning of the next burst. Plateau duration was calculated as the time between the end of a current step and the last spike of the plateau. Because no significant differences in duration, amplitude and frequency of events were detected for combined EC-hippocampal (EC-H) versus isol-EC slices at P8-P10 and P11-P13, data were pooled from both groups of slices. For calculating the effects of $\mathrm{APV}$ or CNQX at P5-P7, data were summarized from sharp fp events
Table 1. Quantitative parameters of the fp events at different postnatal periods

\begin{tabular}{llll}
\hline Period & Peak of amplitude $(\mathrm{mV})$ & Duration $(\mathrm{s})$ & Frequency $(\mathrm{Hz})$ \\
\hline P1-P4 & & & \\
$\quad$ fp events in mEC $(n=6)$ & $0.03 \pm 0.01$ & $0.7 \pm 0.3$ & $\sim 0.004$ \\
$\quad$ fp events in CA3 $(n=29)$ & $0.09 \pm 0.06$ & $0.7 \pm 0.2$ & $0.07(\mathrm{pFE})$ \\
P5-P7 & & & \\
$\quad$ Selective presence & & & \\
$\quad$ fp-sharp $(n=34)$ & $0.16 \pm 0.1$ & $0.9 \pm 0.36$ & $0.08(\mathrm{pFE})$ \\
$\quad$ fp bursts $(n=11)$ & $0.1 \pm 0.08$ & $3.5 \pm 1.2$ & $0.06(\mathrm{pFE})$ \\
$\quad$ Simultaneous presence & & & \\
$\quad(n=8)$ & & & \\
$\quad$ For fp-sharp & $0.08 \pm 0.05$ & $1.19 \pm 0.5$ & \\
$\quad$ For fp bursts & $0.09 \pm 0.06$ & $3.5 \pm 2$ & \\
P8-P10 & & & \\
$\quad$ fp-sharp ( $n=4)$ & $0.08 \pm 0.01$ & $1.7 \pm 0.3$ & $0.16 \pm 0.1$ \\
$\quad \mathrm{fp} \mathrm{bursts}(n=22)$ & $0.03 \pm 0.02$ & $3.2 \pm 0.8$ & $0.1 \pm 0.05$ \\
P11-P13 & & & \\
$\quad$ fp bursts $(n=37)$ & $0.04 \pm 0.02$ & $4.8 \pm 2.5$ & $0.14 \pm 0.06$ \\
\hline
\end{tabular}

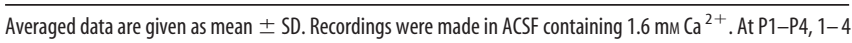
events per 10 min were detected in the $\mathrm{mEC}$ LIII. At P5-P13, all recordings were made in the $\mathrm{mEC} \mathrm{LIII.} \mathrm{For} \mathrm{P5-P7,}$ parameters are calculated for slices with selective presence of sharp $\mathrm{fp}$ events or $\mathrm{fp}$ bursts and for slices with simultaneous appearance of both forms of fp activity.

(fp-sharp) and fp bursts. Frequency of the occurrence of fp events at P5-P7 was calculated from 5 min of recordings under control conditions and in the presence of APV or CNQX. NMDA and AMPA/ kainate receptor-mediated components of synaptic responses as well as antidromic response were identified on the basis of their selective blockade with APV, CNQX, and TTX (see supplemental Fig. 5, available at www.jneurosci.org as supplemental material). For each component the amplitude was calculated as the difference from baseline to peak of the field waveform. Since influence of FFA on intrinsic neuronal excitability may also indirectly affect synaptic responses, we used for the analysis only experiments in which antidromic responses were no significantly changed by FFA (five of seven tested slices). In the remaining two slices FFA reduced amplitude of antidromic components to $73 \pm$ $2 \%$, AMPA/kainate components to $72 \pm 0.4 \%$, and NMDA components to $46 \pm 3 \%$ of the control values. Averaged data are given as mean \pm SD. Paired or unpaired two-tailed Student's $t$ test or Wilcoxon-Mann-Whitney rank sum test was used for statistical comparison.

\section{Results}

We investigated spontaneous activity in the immature mEC by using field potential recordings in LIII and whole-cell patch-clamp recordings from LIII principal neurons in horizontal brain slices.

\section{Periodic spontaneous field activity in the developing mEC}

Extracellular fp recordings were performed in slices obtained from rats at P1-P13. We first determined the patterns of spontaneous fp activity at four sequential postnatal periods: (P1-P4), (P5-P7), (P8-P10), and (P11-P13). All fp recordings were made in $1.6 \mathrm{mM}\left[\mathrm{Ca}^{2+}\right]_{0}$.

We found that at P1-P4, spontaneous fp activity in the mEC was poorly expressed. In 25 of 40 recorded slices (63\%) periodic spontaneous $\mathrm{fp}$ activity in the $\mathrm{mEC}$ was not identified. In 6 of 40 slices (15\%, slices at P2-P4) only individual fp events (1-4 events per $10 \mathrm{~min}$ ) were detected. These fp events were characterized by negative fp deflection and were accompanied by unit discharges (Fig. 1A). In the remaining nine slices $(22 \%)$ only individual unit bursts without fp shifts were observed. In contrast, simultaneous control fp recordings from CA3 area of the hippocampus at $\mathrm{P} 1-\mathrm{P} 4$ showed periodic spontaneous fp events in the majority of tested slices ( 32 of $38 ; 84 \%$ ), similar to what has been reported by Sipilä and colleagues (2005) (Table 1).

The fp recordings in the $\mathrm{mEC}$ at $\mathrm{P} 5-\mathrm{P} 7$ demonstrated periodic spontaneous field events that were characterized by $\sim 0.5-5 \mathrm{~s}$ 
negative-going shifts in the range of $\sim 0.02-$ $0.46 \mathrm{mV}$ (sharp fp events or prolonged $\mathrm{fp}$ events accompanied by field fluctuations) (Fig. 1B). fp events were associated with multiple unit discharges. In the majority of the recorded slices (34 of 53; 64\%) spontaneous $\mathrm{fp}$ activity displayed selective sharp $\mathrm{fp}$ events as illustrated in Figure $1 \mathrm{Ba}$. Prolonged $\mathrm{fp}$ events accompanied by fp fluctuations at $\sim 15-30 \mathrm{~Hz}$ (termed "fp bursts") were observed in $21 \%$ of the recordings (Fig. $1 \mathrm{Bb})$. In the remaining eight slices $(15 \%)$ both forms of fp activity were detected (Fig. $1 B c$ ). Periodic fp activity in the mEC was still present after surgical separation of the hippocampus $(n=25)$ (supplemental Fig. $1 A$, supplemental text, available at www. jneurosci.org as supplemental material), suggesting an involvement of local neuronal circuits within the $\mathrm{EC}$ in this phenomenon. Electrical stimulation of the lateral EC (IEC, $0.1 \mathrm{~ms}, 6-17 \mathrm{~V}$ ) was sufficient to induce sharp fp events or fp bursts, similar to those occurring spontaneously (Fig. 2Aa). fp events could be equally evoked in combined EC-H slices $(n=8)$ as well as in isol-EC slices $(n=4)$.

fp recordings during the second postnatal week revealed a noticeable alteration in the proportion of sharp fp events versus fp bursts. Thus, at postnatal days $8-10$, only a minority of slices ( 4 of $26 ; 15 \%$ ) displayed principal activity that could be distinguished as sharp fp events (Fig. $1 \mathrm{Ca})$. In 22 of 26 slices ( $85 \%)$ the fp recordings showed rhythmic occurrence of fp bursts ( $6 \pm 3 \mathrm{fp}$ bursts/min) (Fig. 1Cb). Data were summarized from 18 EC-H and 8 isol-EC slices. We also observed superimposition (i.e., simultaneous appearance) of sharp fp events and fp bursts (supplemental Fig. $1 \mathrm{~B}$, available at www. jneurosci.org as supplemental material).

Spontaneous fp activity at P11-P13 displayed characteristic slow-wave network rhythmicity (Fig. 1D) in the majority of slices (37 of 43; 86\%; 23 EC-H and 20 isol-EC slices). The pattern was characterized by regular repetitive fp bursts. When stabilized, the frequency of the occurrence of fp bursts was $8.6 \pm 3.6$ events/ min. In 6 of 43 slices we observed just continuous fp fluctuations at $\sim 20-40 \mathrm{~Hz}$, and we were not able to separate individual events. In addition, individual negative $\mathrm{fp}$ deflections [range: $0.5 \pm 0.12 \mathrm{~s}, 0.11 \pm 0.1 \mathrm{mV} ; 1-5$ deflections/10 $\min (n=34)$ ] were simultaneously detected in 13 of 22 and 24 of 37 slices displaying fp bursts at P8-P10 and P11-P13, respectively. Similar to P11-P13, fp activity was also observed in juvenile rats (tested at $\mathrm{P} 14-\mathrm{P} 18 ; n=8$ ). Interestingly, comparable slow-wave oscillations (SWOs) were reported in the EC of adult rats (Cunningham et al., 2006). The quantitative parameters of fp events at different postnatal periods are summarized in Table 1.

A

b

B 0.005. ns, Not significant.
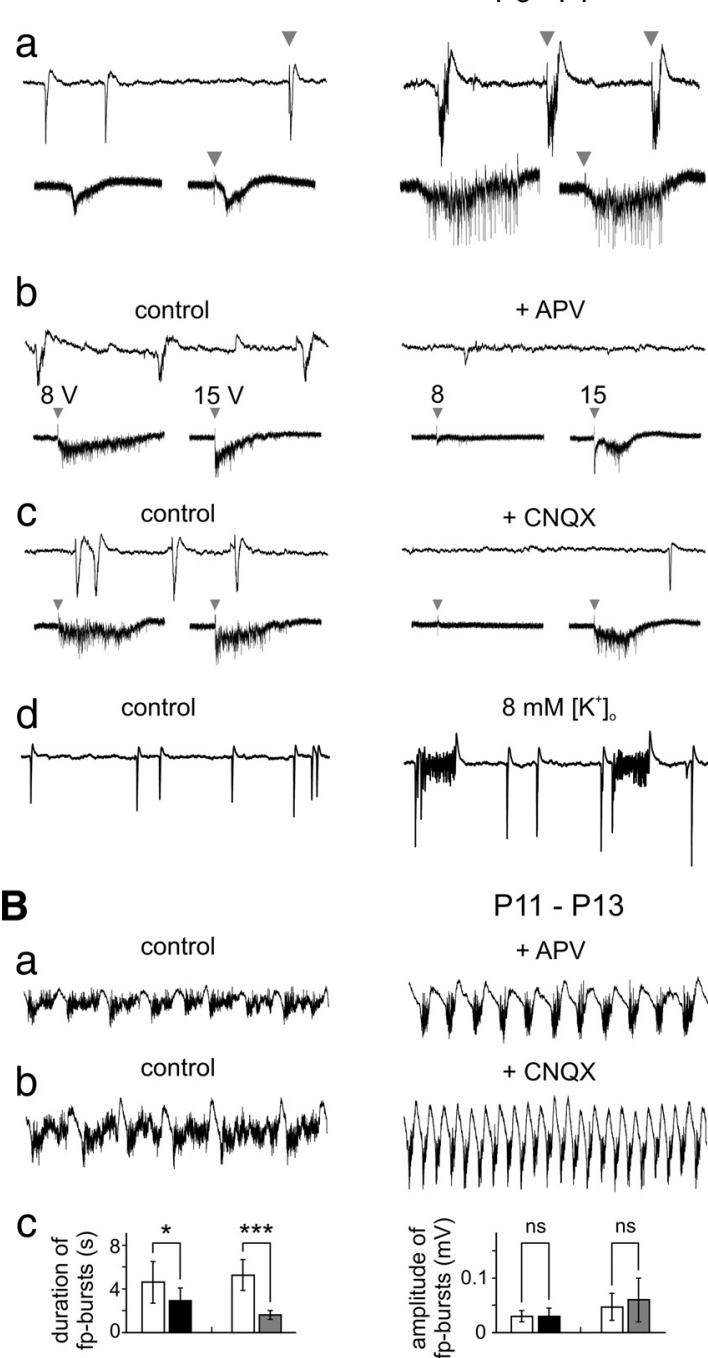

Figure 2. Role of glutamatergic neurotransmission in generation of periodic spontaneous field activity in the $\mathrm{mEC}$ in slices obtained from rats at P5-P7 (A) and P11-P13 (B). Aa, Electrical stimulation of the lateral EC (indicated by arrowheads: left trace, $17 \mathrm{~V}$; right trace, $12 \mathrm{~V}$ ) is sufficient to induce sharp fp events or fp bursts that are comparable to the spontaneous fp events. Right, Durations and peak amplitudes of spontaneous and evoked sharp fp events $(n=5)$ and fp bursts $(n=7)$. $\boldsymbol{A} \boldsymbol{b}, \boldsymbol{c}$, Spontaneous (top) and stimulus-evoked (bottom) fp events (stimuli, 8 and $15 \mathrm{~V}$ for $\boldsymbol{b}$ and $\boldsymbol{c}$, respectively; indicated by arrowheads) in control and during partial and full blockade of iGluRs. The occurrence of spontaneous fp events is strongly reduced in the presence of APV ( 60 $\mu \mathrm{M})$ or CNQX (30 $\mu \mathrm{m})$ and is completely blocked after adding of the mixed NMDA/AMPA/kainate receptor antagonists. Note that strong, but not weak, electrical stimulations are still able to induce fp events in the presence of APV or CNQX (the specimen traces of spontaneous and evoked fp events in the presence of CNQX are shown from different slices). Spontaneous fp activity increases during enhanced tonic excitation following elevation of $\left[\mathrm{K}^{+}\right]_{0}$ and is completely blocked after the addition of CNQX and APV. $\boldsymbol{B}$, Spontaneous slow-wave rhythmic fp activity recorded at P11-P13 is modified after separate adding of APV (a) or CNQX (b) and is fully blocked in the presence of both drugs. $B C$, Duration, peak amplitude, and frequency of $\mathrm{fp}$ bursts during slow-wave activity under control conditions and after adding APV or CNQX. Averaged data are given as mean \pm SD. ${ }^{*} p<0.05,{ }^{* *} p<0.01,{ }^{* * *} p<$

We further investigated the role of ionotropic glutamatergic and GABAergic neurotransmissions in the generation of periodic spontaneous fp events in the developing mEC. At P5-P7, bath application of the NMDAR antagonist APV $(60 \mu \mathrm{M})$ strongly suppressed the periodic spontaneous fp events (both fp-sharp and fp bursts) (seven of nine slices) (percentage of control values; DE: $55 \pm 24 \%, p<0.02$; PA: $109 \pm 41 \%, p=0.6$; frequency of the occurrence: $13 \pm 7 \%, p<0.005)$. Simultaneously, APV prevented appearance of fp events evoked by weak electrical stimulations $(6-10 \mathrm{~V})$. However, in four of six slices an increase in the stimulus intensity (to $\sim 15 \mathrm{~V}$ ) was able to induce fp events in the 

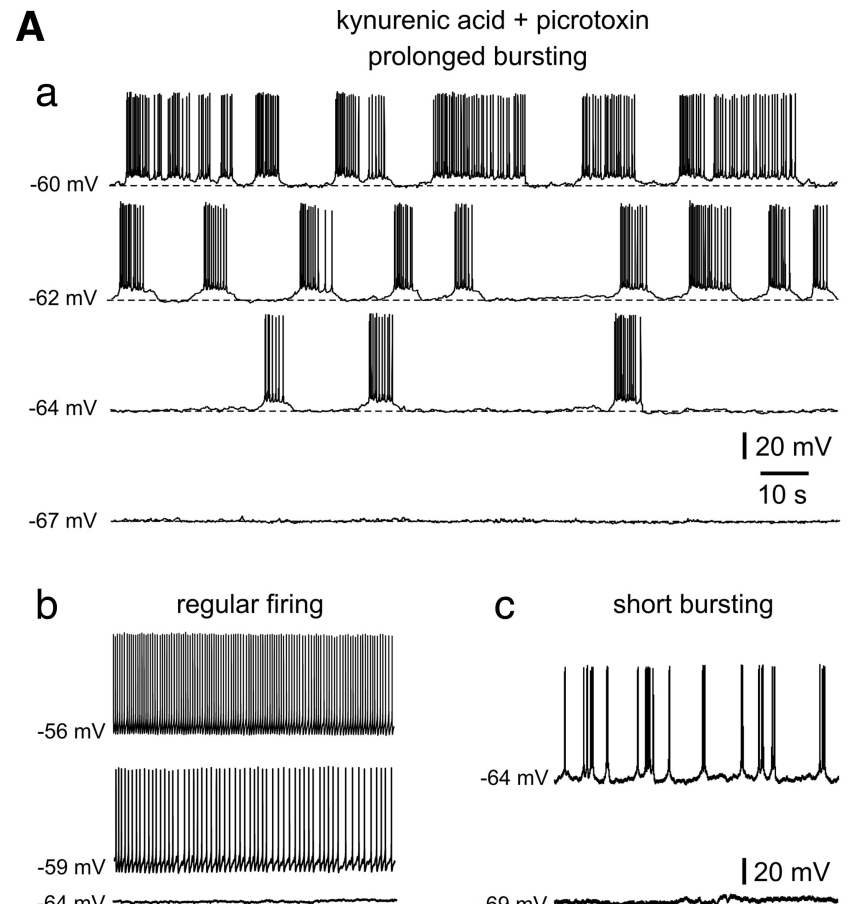

C short bursting
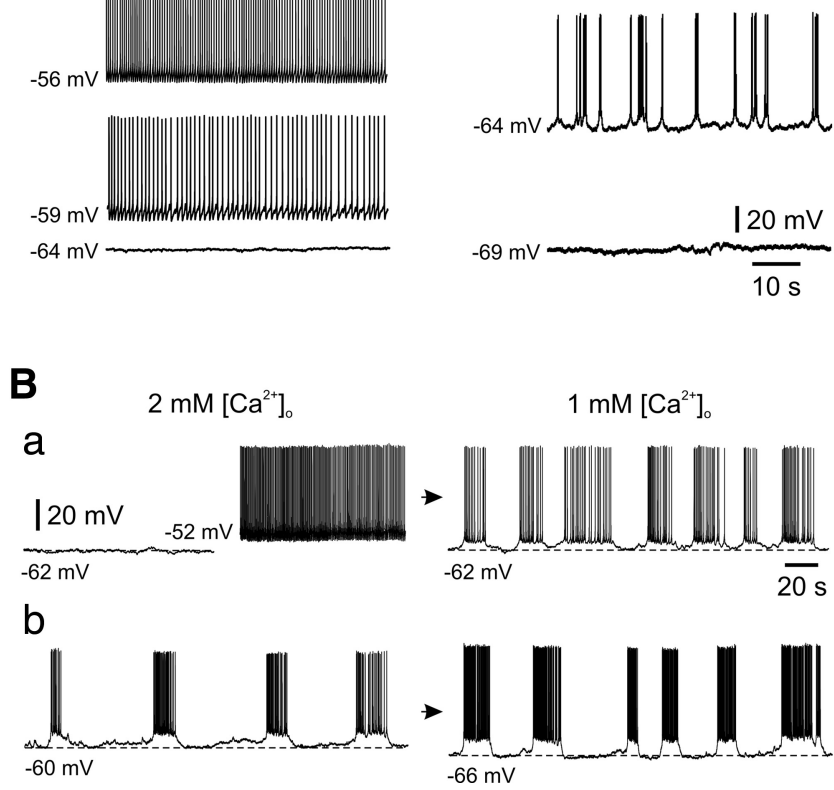

Figure 3. A, Intrinsic firing patterns of developing mEC LIII principal neurons. Aa, Prolonged intrinsic bursting activity of LIII neurons recorded at different membrane potentials. Right, Corresponding histograms of the membrane potential distribution calculated for 160 s show two distinct peaks (bin size, $1 \mathrm{mV}$ ). Regular firing pattern $(\boldsymbol{A} \boldsymbol{b})$ and "short-bursting" pattern (Ac) of LIII neurons. Ac, Right, Membrane potential histograms for the short-bursting pattern were calculated for $60 \mathrm{~s}$ of recording (bin size, $1 \mathrm{mV}$ ). All recordings were made in $2 \mathrm{~mm}\left[\mathrm{Ca}^{2+}\right]_{0} B$, Effects of lowering $\left[\mathrm{Ca}^{2+}\right]_{0}$ on the intrinsic firing pattern of developing $\mathrm{mEC}$ $\mathrm{LIII}$ neurons. $\boldsymbol{B} \boldsymbol{a}$, Switch of regular firing pattern to prolonged-bursting mode after reduction of $\left[\mathrm{Ca}^{2+}\right]_{0}$ from 2 to $1 \mathrm{~mm}$. $\boldsymbol{B} \boldsymbol{b}$, Strengthening of bursts after lowering $\left[\mathrm{Ca}^{2+}\right]_{0}$ by neurons displaying prolonged bursting activity in both $\left[\mathrm{Ca}^{2+}\right]_{0}$ concentrations. All recordings were obtained in the presence of kynurenic acid and picrotoxin. C, Percentage of cells showing prolonged bursting, short bursting, and regular firing activity plotted for the three age groups (P5-P7, P8-P10, and P11-P13). $\left[\mathrm{Ca}^{2+}\right]_{0}$ concentrations indicated on the top of the histogram.

presence of the drug (DE: $70.5 \pm 15 \%$ of control, PA: $97 \pm 19 \%$ of control) (Fig. 2Ab). Similar results were obtained by selective blockade of AMPA/kainate receptors with CNQX (30 $\mu \mathrm{M})$ (Fig. $2 A c)$. CNQX reduced periodic spontaneous activity in five of six cases (percentage of control values; DE: $76 \pm 21 \%, p=0.07$; PA: $112 \pm 33 \%, p=0.46$; frequency of the occurrence: $11 \pm 6 \%, p<$ 0.005). CNQX also blocked fp events evoked by weak but not by strong stimulations $(n=3$ of 4 ; DE: $73 \pm 13 \%$ of control; PA: $64 \pm 47 \%$ of control). Subsequent bath application of mixed NMDA/AMPA/kainate receptor antagonists completely blocked spontaneous fp activity in all tested slices $(n=10)$ and always abolished fp events induced by strong stimulations $(n=8)$ (Fig. $2 A b, A c$ ). Further increase in the stimulus intensity (tested up to $40 \mathrm{~V}$ ) was unable to reinduce fp events in the presence of APV and
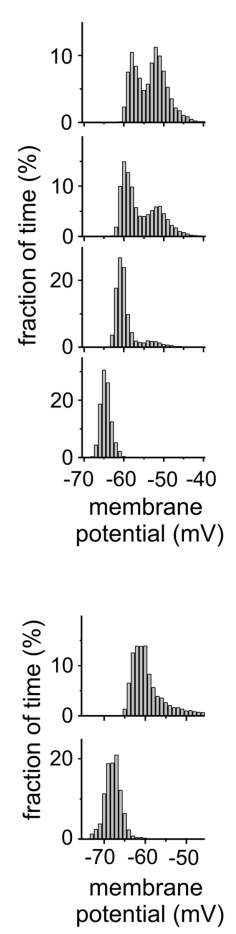

C

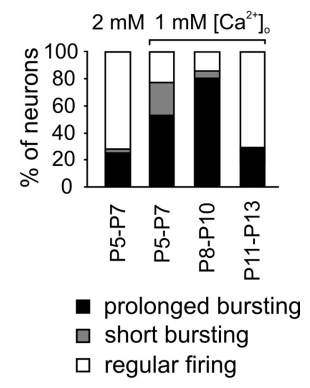

CNQX $(n=8)$. In a minority of cases spontaneous fp events were fully blocked by separate applications APV (two of nine) or CNQX (one of six). All effects of APV and CNQX were reversible after washout of the drugs (proved in six slices). In all tested slices at P5-P7 $(n=5)$, a selective blockage of $\mathrm{GABA}_{\mathrm{A}}$ receptors with picrotoxin $(20 \mu \mathrm{M})$ reversibly elicited spontaneous paroxysmal field discharges (supplemental Fig. 2A, available at www. jneurosci.org as supplemental material), as previously described in the neocortex (Wells et al., 2000), indicating an inhibitory contribution for GABAergic neurotransmission in the immature (P5-P7) mEC.

The above data suggested that the iGluR-mediated neurotransmission as well as the general level of glutamatergic excitation is essential for the initiation of periodic spontaneous fp events in the immature mEC. Therefore, we also tested the effect of iGluR antagonists on fp activity in high-extracellular-potassium $\left(\left[\mathrm{K}^{+}\right]_{\mathrm{o}}\right)$ conditions. Influence of elevated $\left[\mathrm{K}^{+}\right]_{\mathrm{o}}$ on early network activity was previously investigated in the hippocampus (Sipilä et al., 2005) and the somatosensory cortex (Allène et al., 2008). High [ $\left.\mathrm{K}^{+}\right]_{\mathrm{o}}$ increases the recruitment of NMDARs and reduces the excitatory drive provided by immature GABAergic transmission (Rheims et al., 2008) that can modify network patterns. Thus, we first analyzed the influence of tonic depolarization caused by increasing $\left[\mathrm{K}^{+}\right]_{\mathrm{o}}$ on spontaneous $\mathrm{fp}$ activity in the immature $\mathrm{mEC}$.

Increase of $\left[\mathrm{K}^{+}\right]_{\mathrm{o}}$ to $8 \mathrm{mM}$ for $\sim 20 \mathrm{~min}$ resulted in enhanced spontaneous fp activity (Fig. 2Ad; for details, see supplemental material at www.jneurosci.org). In all tested slices $(n=13)$ spontaneous $\mathrm{fp}$ activity was completely blocked after adding CNQX and APV in high- $\left[\mathrm{K}^{+}\right]_{\mathrm{o}}$ conditions (Fig. 2Ad). In contrast, bath application of the gap junction blocker mefloquine (25-50 $\mu \mathrm{M}$; Cruikshank et al., 2004) failed to block spontaneous fp events in control ACSF $(n=6)$ and in high potassium $(n=4)$. Thus, in the presence of $50 \mu \mathrm{M}$ mefloquine neither sharp fp events (percentage of control values in $8 \mathrm{mM}\left[\mathrm{K}^{+}\right]_{\mathrm{o}}$; DE: $99 \pm 42 \%, p=0.9$; PA: $87 \pm 9 \%$, $p=0.9)$ nor fp bursts (DE: $123 \pm 17 \%, p=0.12$; PA: $83 \pm 11 \%, p=$ 0.12 ) were significantly altered.

We further examined the role of iGluRs and $\mathrm{GABA}_{\mathrm{A}}$ Rs in the generation of fp activity during the second postnatal week. In all tested P8-P10 slices, spontaneous and evoked fp events $(n=11$ and 6 respectively) were fully blocked by a mixture of iGluR antagonists, and paroxysmal discharges were observed in the presence of picrotoxin ( $n=8 \mathrm{EC}-\mathrm{H}$ slices). All effects were reversible after washout of the drugs (tested in eight, four, and eight slices for spontaneous, evoked, and paroxysmal fp events, respectively). 
Table 2. Quantitative parameters of the prolonged intrinsic bursting activity at different postnatal periods

\begin{tabular}{|c|c|c|c|c|c|c|c|}
\hline \multirow[b]{2}{*}{ Parameter (mEC LIII) } & \multicolumn{2}{|l|}{$2 \mathrm{~mm}\left[\mathrm{Ca}^{2+}\right]_{0}$} & \multicolumn{5}{|l|}{$1 \mathrm{~mm}\left[\mathrm{Ca}^{2+}\right]_{0}$} \\
\hline & P5-P7 & Versus & P5-P7 & Versus & P8-P10 & Versus & P11-P13 \\
\hline Number of bursts per minute & $2.4 \pm 1.8(n=7)$ & ns & $2.9 \pm 1.2(n=14)$ & $* * *$ & $6.4 \pm 3.5(n=19)$ & ns & $8.1 \pm 2.3(n=10)$ \\
\hline Burst duration (s) & $11.9 \pm 7.4(n=7)$ & ns & $9.9 \pm 6.5(n=14)$ & $* * *$ & $2.9 \pm 1.4(n=19)$ & ns & $2.5 \pm 1.2(n=10)$ \\
\hline Interburst interval (s) & $24.3 \pm 15(n=7)$ & ns & $17.7 \pm 10.5(n=14)$ & * & $9.8 \pm 6.6(n=19)$ & ns & $6.1 \pm 3.6(n=10)$ \\
\hline Burst amplitude (mV) & $5.7 \pm 2.2(n=7)$ & *** & $10.3 \pm 2.9(n=14)$ & ns & $12 \pm 2.4(n=19)$ & ns & $10.7 \pm 4.2(n=10)$ \\
\hline Spike frequency within bursts $(\mathrm{Hz})$ & $2.1 \pm 0.5(n=7)$ & $* * *$ & $4.7 \pm 1.7(n=14)$ & $* * *$ & $10.9 \pm 6(n=19)$ & ns & $9 \pm 4.9(n=10)$ \\
\hline Number of spikes per burst & $23 \pm 12(n=7)$ & * & $47 \pm 46(n=14)$ & ns & $32 \pm 26(n=19)$ & ns & $22 \pm 16(n=10)$ \\
\hline Spike threshold (mV) & $-44.4 \pm 2.7(n=7)$ & ns & $-41.3 \pm 3.4(n=10)$ & ** & $-47 \pm 4.3(n=14)$ & $* *$ & $-53 \pm 4(n=8)$ \\
\hline AHP amplitude (mV) & $2.6 \pm 0.5(n=3)$ & ns & $3.6 \pm 1.2(n=8)$ & ns & $3.8 \pm 1.4(n=18)$ & ns & $3.8 \pm 1.5(n=7)$ \\
\hline AHP duration (s) & $17.5 \pm 3.5(n=3)$ & ns & $18.8 \pm 17(n=8)$ & $* * *$ & $4.6 \pm 3.6(n=18)$ & ns & $3.4 \pm 2(n=7)$ \\
\hline Input resistance (GOhm) & $1.2 \pm 0.1(n=4)$ & ns & $1.2 \pm 0.3(n=11)$ & $* * *$ & $0.6 \pm 0.1(n=8)$ & $* * *$ & $0.4 \pm 0.06(n=6)$ \\
\hline Recording membrane potential (mV) & $-60 \pm 2.5(n=7)$ & ns & $-60.5 \pm 1.3(n=14)$ & ns & $-62 \pm 2.6(n=19)$ & ns & $-63 \pm 2.5(n=10)$ \\
\hline
\end{tabular}

Averaged data are given as mean \pm SD. Recordings were made in ACSF containing $2 \mathrm{~mm}$ or $1 \mathrm{~mm} \mathrm{Ca}{ }^{2+}$ as indicated on the top. iGluRs and GABA Rs were blocked as detailed in Materials and Methods. Unpaired two-tailed $t$ test or Mann-Whitney rank sum test (versus, i.e., left versus right) values are indicated as follows: ${ }^{*} p<0.05,{ }^{* *} p<0.01,{ }^{* * *} p<0.005$. ns, Not significant.

In the adult EC, it has been reported that generation of SWOs is mediated by activation of kainate (GluR5) receptors in a recurrent network of pyramidal neurons (Cunningham et al., 2006). Application of CNQX or specific GluR5 receptor antagonist UBP-302 abolished this rhythmic activity in the adult EC. In contrast, we found that CNQX failed to block spontaneous slowwave network rhythmicity in the mEC at P11-P13 ( $n=8$ of 8$)$. fp activity was significantly affected by APV $(n=4)$ as well as by CNQX $(n=5)$ and was always fully blocked in the presence of both drugs $(n=14)$ (Fig. $2 B)$, indicating a conjoined contribution of NMDA and AMPA/kainate receptors in shaping the dynamics of slow-wave network rhythmicity at P11-P13. Blockade of slow-wave activity by a mixture of iGluR antagonists was reversible after washout of the drugs (tested in seven slices). In three of eight experiments with APV, the NMDAR antagonist was able to prevent slow-wave activity independently. Finally, in all tested slices at P11-P13 ( $n=10$; eight isol-EC and two EC-H slices) picrotoxin reversibly induced spontaneous rhythmic paroxysmal discharges (supplemental Fig. $2 B$, available at www.jneurosci.org as supplemental material).

\section{Patterns of intrinsic firing activity of developing mEC neurons}

We further investigated the intrinsic firing pattern of mEC LIII principal neurons at P5-P13 with the goal to detect spontaneously active cells. Recordings were obtained during blockade of glutamatergic and GABAergic neurotransmission with a drug mixture consisting of either a mixture of kynurenic acid (2 mM) and picrotoxin $(100 \mu \mathrm{M})$, or a mixture of APV $(60 \mu \mathrm{M})$, CNQX $(30 \mu \mathrm{M})$, and picrotoxin $(100 \mu \mathrm{M})$. Under these conditions, we identified three distinct patterns of intrinsic firing behavior.

We found that a fraction of immature LIII neurons spontaneously generated prolonged ( $\sim 2-20 \mathrm{~s})$ voltage-dependent intrinsic bursting activity, as illustrated in Figure 3Aa. At P5-P7, in standard bicarbonate-based ACSF containing $2 \mathrm{mM} \mathrm{Ca}^{2+}, 25 \%$ of the neurons ( 22 of 88 ) displayed such a prolonged bursting pattern. This pattern was characterized by a slow periodic $(\sim 0.01-0.1 \mathrm{~Hz})$ membrane depolarization $(\sim 6 \mathrm{mV})$ with superimposed spike discharges. Spiking activity during prolonged depolarization was almost regular; however, it occasionally included short-duration (up to $\sim 1 \mathrm{~s}$ ) bursts. Prolonged bursts of spikes were preceded by a slow regenerative depolarization, which started at approximately $-64 \mathrm{mV}$, and was followed by a small afterhyperpolarization (AHP). Duration of prolonged bursts increased and interburst interval decreased with membrane depolarization; however, the averaged frequency (i.e., number of bursts per minute) did not significantly change with membrane depolarization $(n=9)$ (supplemental Fig. $3 A$, available at www.jneurosci.org as supplemental material). Indeed, negative current injection (membrane hyperpolarization beyond approximately $-70 \mathrm{mV}$ ) led to silencing (Fig. 3Aa); in initially silent neurons, depolarizing current injection to approximately $-60 \mathrm{mV}$ produced bursting activity. The resting membrane potential (RMP) of the neurons was $-61.8 \pm 3 \mathrm{mV}(n=12)$. The histogram of membrane potential distribution of prolongedbursting neurons showed two distinct peaks reflecting the two states of membrane potential (Fig. $3 A a$, right). The quantitative parameters of prolonged intrinsic bursts are summarized in Table 2. Prolonged bursting activity recorded during intact neurotransmission displayed similar characteristics but was accompanied by brief synaptically mediated bursts that remained after negative current injection to voltage levels below approximately $-68 \mathrm{mV}(n=4)$ (supplemental Fig. $3 B$, available at www.jneurosci.org as supplemental material). Since whole-cell recordings accompanied by intracellular dialysis with the pipette filling solution could modify firing pattern, we used the cellattached configuration to confirm bursting behavior of intact mEC neurons. Robust prolonged bursting activity similar to the whole-cell recordings was detected in the cell-attached configuration $(n=23)$ (supplemental Fig. 3C, supplemental Table 1, available at www.jneurosci.org as supplemental material), indicating that this burst firing is a physiological firing mode of developing mEC LIII neurons.

The majority of LIII neurons $(72 \%, 63$ of 88 at P5-P7 in $2 \mathrm{~mm}$ $\left[\mathrm{Ca}^{2+}\right]_{\mathrm{o}}$ ) displayed a nonbursting (regular) pattern of activity, as illustrated in Figure $3 A b$ [i.e., neurons were silent at the RMP and showed regular firing activity following membrane depolarization; RMP: $-60.7 \pm 3.7 \mathrm{mV}(n=25)$; input resistance (IR): $1.2 \pm$ 0.2 GOhm $(n=4)]$. The remaining $3 \%$ of neurons $(n=3)$ showed a spontaneous activity that was classified as "short bursting" (Fig. 3Ac). This pattern was characterized by the exclusive presence of short-duration $(<2 \mathrm{~s})$ suprathreshold membrane depolarization, including a complex of two to four fast spikes (RMP: $-60 \pm 3.1 \mathrm{mV}$; IR: $1.1 \pm 0.2 \mathrm{GOhm}$ ). The histogram of membrane potential displayed one peak distribution (Fig. $3 A c$, right).

Thus, at P5-P7, in ACSF containing $2 \mathrm{mM} \mathrm{Ca}^{2+}$ the proportions of neurons with prolonged bursting, regular firing, and short bursting activity were 25,72 , and $3 \%$, respectively. However, recordings in $1 \mathrm{~mm}\left[\mathrm{Ca}^{2+}\right]_{\mathrm{o}}$ resulted in an increased fraction of neurons with prolonged bursting to 53\% (49 of 92 neurons) and with short bursting to $24 \%(n=22)$. At the same 
A

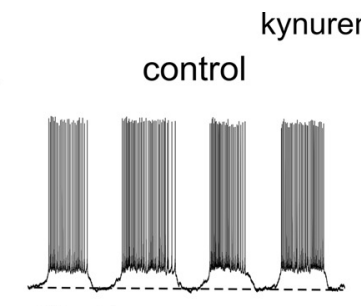

$-68 \mathrm{mV}$

B

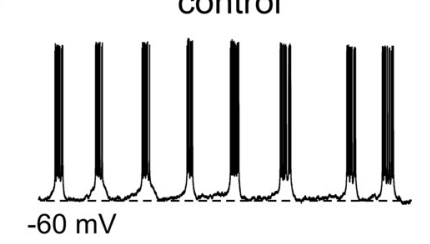

C

control

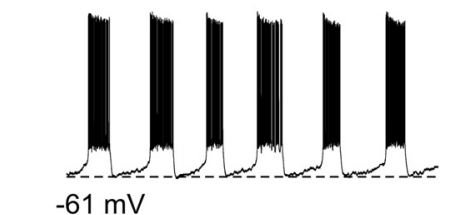

D

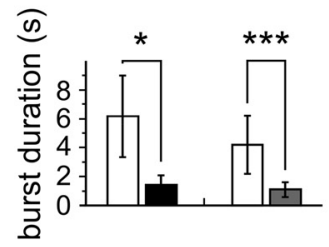

E

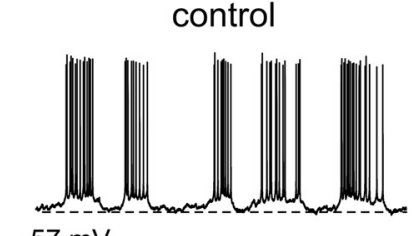

$-57 \mathrm{mV}$
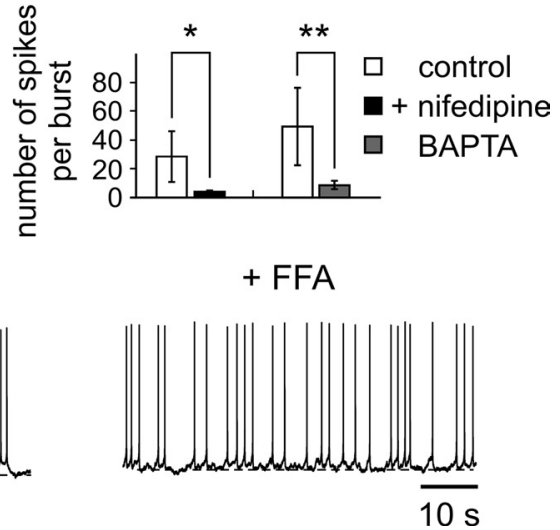

Figure 4. $I_{\text {CAN }}$ underlies the prolonged intrinsic bursts. $\boldsymbol{A}$, Prevention of prolonged bursting activity after blockade of $\mathrm{Ca}^{2+}$ channels with cadmium $\left(\mathrm{Cd}^{2+}, 100 \mu \mathrm{m}\right)$. Right, Part of the trace marked on the left-hand side shown at an expanded time scale. Note that short bursts of spikes are still present after positive current injection in the presence of $\mathrm{Cd}^{2+}$ (indicated by gray arrowhead). B, Nifedipine (50 $\mu \mathrm{m}$ ) strongly suppressed prolonged bursts. $C$, Intracellular application of the calcium chelator BAPTA $(30 \mathrm{~mm})$ abolish prolonged bursts. Current injection is indicated under right-hand trace. $\boldsymbol{D}$, Burst duration and number of spikes per burst under control conditions and in the presence of 50-100 $\mu \mathrm{m}$ nifedipine $(n=7)$ or after buffering intracellular $\mathrm{Ca}^{2+}$ with BAPTA $(n=8)$. Averaged data are given as mean \pm SD. ${ }^{*} p<0.05,{ }^{* *} p<0.01,{ }^{* * *} p<0.005$. E, FFA (50 $\left.\mu \mathrm{m}\right)$ blocks prolonged intrinsic bursting activity. All recordings were made in the presence of kynurenic acid and picrotoxin.

time, we observed a reduction in the amount of the regularly firing cells to $23 \%(n=21)$. These results indicate that depending on $\left[\mathrm{Ca}^{2+}\right]_{\mathrm{o}}$ some neurons may switch from one firing mode to the other. Indeed, as illustrated in Figure $3 B a$, we found that the regular firing pattern observed in $2 \mathrm{mM}\left[\mathrm{Ca}^{2+}\right]_{0}$ can switch to the prolonged bursting activity after a reduction of $\left[\mathrm{Ca}^{2+}\right]_{0}$ to $1 \mathrm{mM}$ ( $n=3$ of 7 tested neurons). Nevertheless, four of seven neurons displayed prolonged bursting activity in both tested $\left[\mathrm{Ca}^{2+}\right]_{\mathrm{o}}$ concentrations (Fig. $3 \mathrm{Bb}$ ). On average, lowering $\left[\mathrm{Ca}^{2+}\right]_{\mathrm{o}}$ to $1 \mathrm{~mm} \mathrm{did}$ not affect the occurrence of bursts and burst duration. However, reduction of $\left[\mathrm{Ca}^{2+}\right]_{\mathrm{o}}$ significantly increased the burst amplitude as well as spike frequency within bursts (Table 2). The amount of neurons generating the prolonged bursting pattern peaked around $\mathrm{P} 8-\mathrm{P} 10$, and then at P11-P13 strongly decreased. In 1 $\mathrm{mM}\left[\mathrm{Ca}^{2+}\right]_{\mathrm{o}}$, percentages of neurons showing prolonged bursting, short bursting, and regular firing activity, were 81,5 , and
$14 \%$, respectively, at $\mathrm{P} 8-\mathrm{P} 10(n=44)$, and 29,0 , and $71 \%$, respectively, at P11P13 $(n=49)$ (Fig. $3 C)$. Significant alterations in parameters of prolonged intrinsic bursting were observed at $\mathrm{P} 8-\mathrm{P} 10$ versus $\mathrm{P} 5-\mathrm{P} 7$, but not at $\mathrm{P} 11-\mathrm{P} 13$ versus $\mathrm{P} 8-\mathrm{P} 10$ (Table 2). Basically, the occurrence of bursts increased and burst duration markedly decreased during the first two postnatal weeks (tested from P5). Similar alterations were also observed in the cellattached patch recordings (supplemental Table 1, available at www.jneurosci.org as supplemental material). At P8-P10 and P11-P13, membrane hyperpolarization beyond approximately $-70 \mathrm{mV}$ always led to silencing.

The prolonged intrinsic bursting activity was no longer detected in the third postnatal week [tested in $1 \mathrm{~mm}\left[\mathrm{Ca}^{2+}\right]_{\mathrm{o}}$ by using whole-cell $(n=6)$ and sharp microelectrode $(n=10)$ recordings]. Thus, the described phenomenon may selectively contribute to early postnatal development.

\section{Ionic mechanisms of prolonged intrinsic bursting activity in developing mEC neurons}

We next investigated the mechanisms underlying intrinsic bursting. Knowing that $\mathrm{Ca}^{2+}$-dependent mechanisms are often involved in burst generation, we focused on the possible involvement of the $\mathrm{Ca}^{2+}$ activated nonspecific cationic current $\left(I_{\mathrm{CAN}}\right)$. To examine the role of extracellular $\mathrm{Ca}^{2+}$ influx, we first blocked $\mathrm{Ca}^{2+}$ channels with cadmium $\left(\mathrm{Cd}^{2+}, 100 \mu \mathrm{M}\right)$. This prevented the cells' ability to generate prolonged bursts $(n=8)$ (Fig. $4 A$ ), suggesting that $\mathrm{Ca}^{2+}$ influx associated with spiking is required. Since spiking is expected to lead to $\mathrm{Ca}^{2+}$ influx through high-voltage-activated $\mathrm{Ca}^{2+}$ channels, we tested the effect of the L-type $\mathrm{Ca}^{2+}$ channel blocker nifedipine $(10-100 \mu \mathrm{M})$. As illustrated in Figure $4, B$ and $D$, nifedipine $(50-100 \mu \mathrm{M})$ strongly affected the prolonged bursting activity in all cases tested. Ten micromoles of nifedipine modified regular firing during prolonged bursts into complex spikes $(n=2)$. We also found that high concentrations of intracellular BAPTA, a high-affinity $\mathrm{Ca}^{2+}$ chelator, abolished prolonged bursts (Fig. $4 C, D$ ) (BAPTA vs control; spike frequency within burst: $11.4 \pm$ $5.6 \mathrm{~Hz}$ vs $14.6 \pm 4.5 \mathrm{~Hz}, p<0.05$; number of bursts per minute: $10 \pm 2.5$ vs $5 \pm 2, p<0.02, n=8)$. Moreover, prolonged intrinsic bursting activity was completely blocked by FFA ( $50 \mu \mathrm{M}, n=8)$ (Fig. $4 E$ ), a nonselective blocking agent of $I_{\mathrm{CAN}}$ (Partridge and Valenzuela, 2000), suggesting a contribution of $I_{\mathrm{CAN}}$ to the phenomenon. However, following positive current injections, short bursts of spikes were still observed in the presence of $\mathrm{Cd}^{2+}$ or BAPTA (Fig. 4). This could be a result of the persistent $\mathrm{Na}^{+}$ current $\left(I_{\mathrm{Nap}}\right)$ which is likely to be involved in the initiation phase of prolonged bursts and possibly in the "up phase" of bursts. 
Spikes triggered by $I_{\mathrm{Nap}}$ possibly elicit an increase of the intracellular $\mathrm{Ca}^{2+}$ concentration $\left(\left[\mathrm{Ca}^{2+}\right]_{\mathrm{i}}\right)$ required for the activation of $I_{\mathrm{CAN}}$. Indeed, prolonged bursting activity was completely blocked by TTX ( 1 $\mu \mathrm{M}, n=4$ ) (Fig. 5A), an antagonist of both $\mathrm{Na}^{+}$currents $\left[I_{\text {Nap }}\right.$ and transient $\mathrm{Na}^{+}$current $\left.\left(I_{\mathrm{Nat}}\right)\right]$. Furthermore, prolonged bursts were strongly suppressed by riluzole $(5-10 \mu \mathrm{M}, n=10)$ (Fig. $5 B$ ), a drug that affects $I_{\text {Nap }}$ at far lower concentrations than $I_{\mathrm{Nat}}$ [e.g., $\mathrm{IC}_{50}$ of 2 vs $50 \mu \mathrm{M}$, respectively (Urbani and Belluzzi, 2000)], pointing to an involvement of the $I_{\mathrm{Nap}}$ in triggering and/or sustaining prolonged bursts (riluzole vs control; spike frequency in bursts: $1.9 \pm 0.9 \mathrm{~Hz}$ vs $3.9 \pm 2$ $\mathrm{Hz}, p<0.02$; burst amplitude: $8.9 \pm 2.8 \mathrm{~s}$ vs $10.9 \pm 3.7 \mathrm{~s}, p=0.08, n=7)$. Moreover, we found that a $0.2-1$ s suprathreshold current step stimulus was able to elicit a terminated plateau potential in prolonged-bursting $(n=31)$ (Fig. $6 A$ ) but not in regularly firing $(n=11)$ or short-bursting $(n=6)$ neurons. The depolarizing plateau potential displayed pronounced activity and voltage dependence (Fig. 6Ab; supplemental Fig. 4, available at www.jneurosci.org as supplemental material). Thus, increasing the duration or intensity of the trigger pulse as well as the steady depolarization of the membrane potential led to an increase in the duration of the plateau, but never gave rise to a stable state of sustained spiking. In general, a $0.5-1 \mathrm{~s}$ long spike train at $4-8 \mathrm{~Hz}$ evoked from a resting level of $\sim 15 \mathrm{mV}$ or less from spike threshold almost invariably elicited plateau potentials with a duration of $\sim 5 \mathrm{~s}$ at P5-P7. Repetitively (1-5 s after discharges) applied suprathreshold depolarizing pulses revealed refractoriness of the plateau potential $(n=10)$ (Fig. 6Ac). Recovery from the refractoriness required $\sim 10 \mathrm{~s}$. The basic characteristics of the plateau potential in prolonged-bursting neurons recorded in $1 \mathrm{~mm}$ $\left[\mathrm{Ca}^{2+}\right]_{\mathrm{o}}$ at different postnatal periods are summarized in Table 3 . We also tested whether local synaptic activation could also induce plateau potential in $\mathrm{mEC}$ neurons. To eliminate a possible contribution of NMDARs to the plateau, experiments were made in the presence of APV $(30 \mu \mathrm{M})$. As illustrated in Figure $6 B$, electrical stimulation of the lEC $(0.2 \mathrm{~ms}, 20-30 \mathrm{~V})$ was sufficient to induce terminated plateau potentials, comparable to those inducing by current step stimulus $(n=4)$. The terminated plateau potential response to current steps was blocked by $30 \mathrm{~mm}$ BAPTA applied intracellularly through the patch pipette solution for $\sim 20$ $\min (n=8)$ or by $50 \mu \mathrm{M}$ FFA $(n=5)$ (Fig. $7 A, B)$. The plateau was suppressed by $10 \mu \mathrm{M}$ riluzole $(n=4)$ (plateau amplitude: $8.8 \pm$ $2.3 \mathrm{mV}$ in riluzole vs $10.5 \pm 0.7 \mathrm{mV}$ in control) (Fig. 7C). The effects of BAPTA, FFA, and riluzole on the plateau are comparable to their effects on spontaneous prolonged bursting activity. These results suggest that both $I_{\mathrm{CAN}}$ and $I_{\mathrm{Nap}}$ are involved in the generation of plateau potentials as well as in "up phase" of prolonged bursts. Importantly, elevation of $\left[\mathrm{Ca}^{2+}\right]_{\mathrm{o}}$ from 1 to $2 \mathrm{mM}$ resulted in a switch from prolonged bursting activity to regular firing and was also accompanied by the disappearance of the plateau potential $(n=4)$ (Fig. $7 D)$.

kynurenic acid + picrotoxin

control

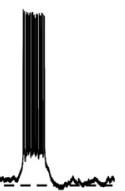

control

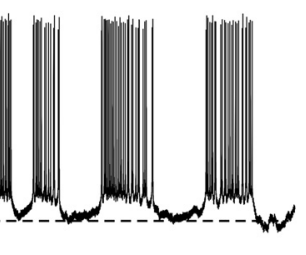

control

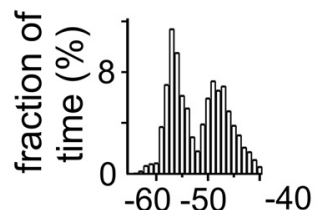

membrane potential $(\mathrm{mV})$

+ riluzole

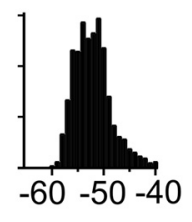

+ TTX

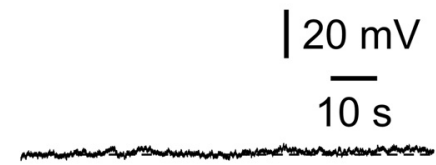

+ riluzole

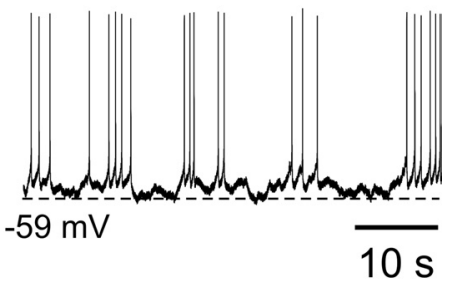

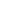 \\ (1)}

Figure 5. $\mathrm{Na}^{+}$currents are involved in the generation of prolonged intrinsic bursting activity. $\boldsymbol{A}, \mathrm{TTX}(1 \mu \mathrm{M})$ completely blocks spontaneous bursting activity. $\boldsymbol{B}$, Riluzole $(10 \mu \mathrm{m})$ strongly suppress prolonged bursting activity. The corresponding histogram of membrane potential distribution calculated for 50 s of recording (bin size, $1 \mathrm{mV}$ ) shows two distinct peaks in control conditions and one peak in the presence of riluzole (bottom). All recordings were obtained in the presence of kynurenic acid and picrotoxin.

In the thalamus, the mechanism underlying the generation of the "up state" in the slow oscillation critically relies on the window component of the low-voltage-activated $\mathrm{Ca}^{2+}$ current $(\mathrm{T}$ type) (Crunelli et al., 2005, Blethyn et al., 2006). Moreover, $\mathrm{Ca}^{2+}$ entry through T-type channels may activate $I_{\mathrm{CAN}}$ (Bal and McCormick, 1993). To investigate a possible contribution of T-type $\mathrm{Ca}^{2+}$ channels in the generation of prolonged intrinsic bursts, we performed additional experiments in the presence of $100 \mu \mathrm{M} \mathrm{Ni}^{2+}$, a concentration that preferentially blocks T-type $\mathrm{Ca}^{2+}$ channels. Addition of $\mathrm{Ni}^{2+}$ did not affect prolonged bursting activity of mEC LIII neurons $(n=3)$ (supplemental Table 2, available at www.jneurosci.org as supplemental material). To analyze whether $\mathrm{Ca}^{2+}$-activated $\mathrm{K}^{+}$currents $\left(I_{\mathrm{AHP}}\right)$ play a role in the termination of prolonged bursts, TEA $(1 \mathrm{mM})$ was applied at a concentration that blocks the large-conductance $\mathrm{Ca}^{2+}$ dependent $\mathrm{K}^{+}$current (BK current). As illustrated in Figure $8 \mathrm{~A}$, TEA elicited a strong prolongation of burst duration with a simultaneous increase in burst amplitude (supplemental Table 3, available at www.jneurosci.org as supplemental material). Duration and amplitude of plateau potentials triggered by depolarizing current steps were also enhanced in the presence of TEA (Fig. $8 B$; also supplemental Table 4 , available at www.jneurosci.org as supplemental material). We also tested neurons in the presence of the group I and II metabotropic glutamate receptor (mGluR) antagonist E4CPG to exclude a possible early mGluR-dependent firing (Yoshida et al., 2008). Bath application of the E4CPG (200 $\mu \mathrm{M})$ did not abolish the prolonged intrinsic bursting activity of immature mEC LIII neurons $(n=4)$. The prolonged intrinsic bursting activity in $\mathrm{mEC}$ LIII neurons was also observed in the presence of atropine $(10 \mu \mathrm{M}, n=4)$, indicating that cholinergic 


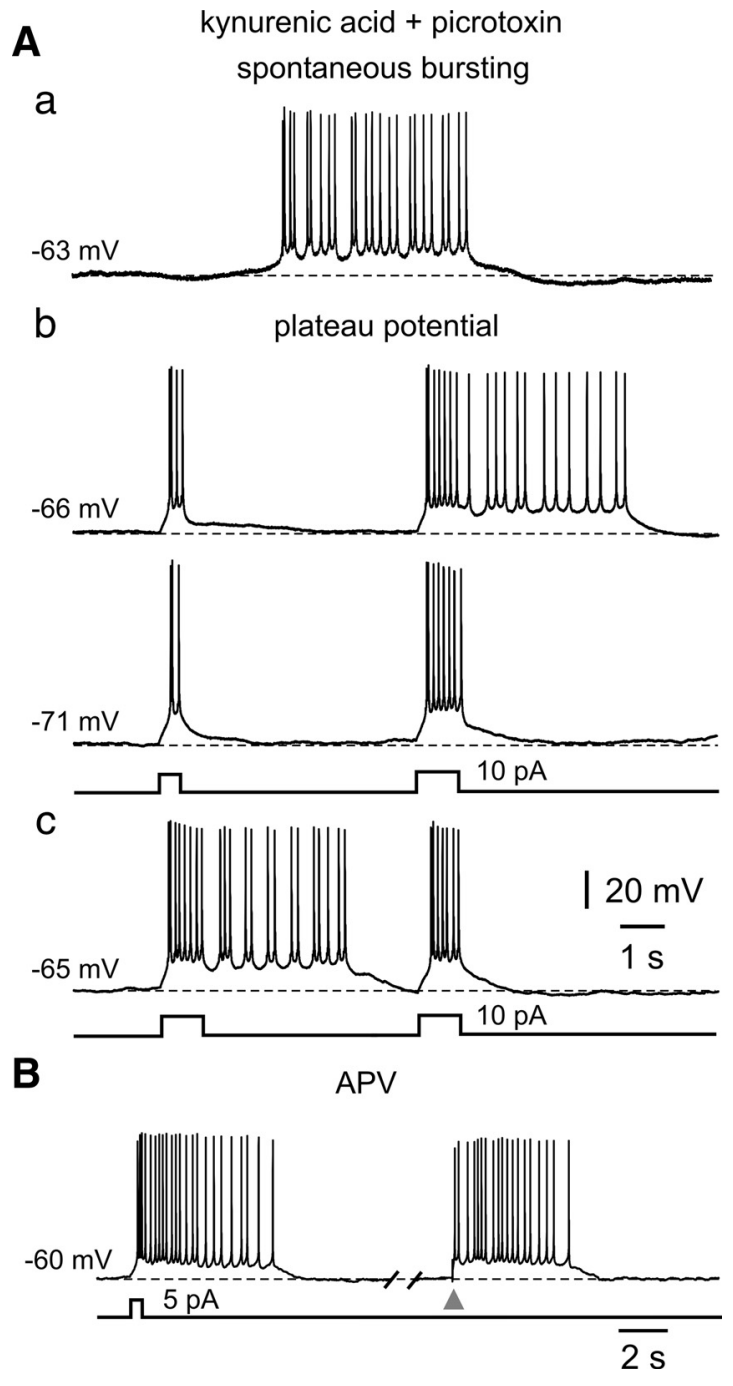

Figure 6. Plateau potential in immature mEC LIII neurons. Aa, Spontaneous intrinsic bursting activity under control conditions. $\boldsymbol{A} \boldsymbol{b}$, In the same neuron a short (1 $\mathrm{s}$ ) suprathreshold current step stimulus is sufficient to elicit a terminated plateau potential. The bottom trace shows responses to equal current steps after membrane hyperpolarization. $\boldsymbol{A c}$, Repetitively applied suprathreshold depolarizing pulse reveals refractoriness of the plateau potential. Recordings were made in $2 \mathrm{~mm}\left[\mathrm{Ca}^{2+}\right]_{0}$ in the presence of kynurenic acid and picrotoxin. $\boldsymbol{B}$, Plateau potential induced by current step stimulus (left) and by electrical stimulation (right) in the same neuron. Stimulation of the IEC $(0.2 \mathrm{~ms}, 30 \mathrm{~V})$ is indicated by the arrowhead. Recording was made in $1 \mathrm{~mm}\left[\mathrm{Ca}^{2+}\right]_{0}$ in the presence of APV $(30 \mu \mathrm{M})$.

muscarinic-dependent spiking (Tahvildari et al., 2008) does not underlie this phenomenon.

\section{Effects of lowering $\left[\mathrm{Ca}^{2+}\right]_{\mathrm{o}}$ and inhibitors of prolonged intrinsic bursts on the periodic spontaneous field activity in the developing $\mathrm{mEC}$}

We further investigated the potential contribution of intrinsic bursting to the periodic spontaneous field events. The above results had shown that lowering $\left[\mathrm{Ca}^{2+}\right]_{\mathrm{o}}$ increased the tendency of $\mathrm{mEC}$ LIII neurons to generate bursts. We next examined whether lowering of $\left[\mathrm{Ca}^{2+}\right]_{\mathrm{o}}$ from 1.6 to $1 \mathrm{~mm}$ affects spontaneous $\mathrm{fp}$ activity in the $\mathrm{mEC}$.

No obvious alterations in fp activity after lowering of $\left[\mathrm{Ca}^{2+}\right]_{\mathrm{o}}$ were identified in slices at P1-P4. Periodic spontaneous fp activity was not identified in 11 of 22 tested slices (50\%). In six slices (27\%) individual negative fp deflections (range: $0.7 \pm 0.2 \mathrm{~s}$, $0.06 \pm 0.03 \mathrm{mV}, \sim 2-20$ deflections $/ 10 \mathrm{~min}$ ) accompanied by
Table 3. Quantitative parameters of the plateau potential at different postnatal periods

\begin{tabular}{|c|c|c|c|c|c|}
\hline \multirow[b]{2}{*}{ Parameter (mEC LIII) } & \multicolumn{5}{|l|}{$1 \mathrm{~mm}\left[\mathrm{Ca}^{2+}\right]_{0}$} \\
\hline & $\begin{array}{l}\text { P5-P7 } \\
(n=10)\end{array}$ & Versus & $\begin{array}{l}\mathrm{P} 8-\mathrm{P} 10 \\
(n=6)\end{array}$ & Versus & $\begin{array}{l}\mathrm{P} 11-\mathrm{P} 13 \\
(n=5)\end{array}$ \\
\hline Plateau duration (s) & $4.8 \pm 1.8$ & * & $2.8 \pm 1.7$ & ns & $2.7 \pm 0.7$ \\
\hline Plateau amplitude (mV) & $9.2 \pm 2.3$ & ns & $11.6 \pm 3.7$ & ns & $11.3 \pm 2.5$ \\
\hline $\begin{array}{l}\text { Spike frequency within } \\
\text { plateau }(\mathrm{Hz})\end{array}$ & $4.4 \pm 1.3$ & $* *$ & $14.8 \pm 10.6$ & ns & $11.5 \pm 0.6$ \\
\hline $\begin{array}{l}\text { Number of spikes within } \\
\text { plateau }\end{array}$ & $21 \pm 11$ & ns & $32 \pm 17$ & ns & $31 \pm 6$ \\
\hline AHP amplitude (mV) & $3.2 \pm 0.9$ & ns & $3.4 \pm 1.4$ & ns & $4 \pm 1.3$ \\
\hline AHP duration (s) & $12.6 \pm 8.5$ & ns & $6.5 \pm 2.4$ & ns & $7 \pm 4.6$ \\
\hline $\begin{array}{l}\text { Recording membrane } \\
\text { potential }(\mathrm{mV})\end{array}$ & $-63.5 \pm 3.2$ & ns & $-63.1 \pm 2.6$ & ns & $-62.8 \pm 1.3$ \\
\hline
\end{tabular}

Averaged data are given as mean \pm SD. The plateau potential was induced by depolarizing current steps ( $5-10 \mathrm{pA}$ $0.2-1 \mathrm{~s})$. Recordings were made in ACSF containing $1 \mathrm{~mm} \mathrm{Ca}{ }^{2+}$. iGluRs and $\mathrm{GABA}_{\mathrm{A}} \mathrm{Rs}$ were blocked as detailed in Materials and Methods. Unpaired two-tailed $t$ test or Mann-Whitney rank sum test (versus, i.e., left versus right) values are indicated as follows: ${ }^{*} p<0.05,{ }^{* *} p<0.01$. ns, Not significant.

unit discharges were observed, and in the remaining five slices $(23 \%)$ only individual unit bursts were detected.

At P5-P7, spontaneous sharp fp events were not significantly changed after reduction of $\left[\mathrm{Ca}^{2+}\right]_{\mathrm{o}}$ in all six EC-H slices showing selective sharp fp events in control (Fig. 9Aa,Ad). However, lowering of $\left[\mathrm{Ca}^{2+}\right]_{\mathrm{o}}$ in slices with a selective fp burst activity in control conditions induced a prolongation of fp bursts $(n=7)$ (Fig. 9Aa,Ad). Frequency of the occurrence of fp events was slightly, but not significantly, increased after reduction of $\left[\mathrm{Ca}^{2+}\right]_{\mathrm{o}}$ to $1 \mathrm{~mm}$ (sharp fp events: $111 \pm 14 \%$ of control, $n=6$, $p=0.17$; fp burst: $133 \pm 41 \%$ of control, $n=6, p=0.11$ ).

At $\mathrm{P} 8-\mathrm{P} 10$, reduction of $\left[\mathrm{Ca}^{2+}\right]_{\mathrm{o}}$ to $1 \mathrm{~mm}$ reversibly induced a prolongation of fp bursts in slices displaying rhythmic fp bursting under control conditions $(n=8)$ (Fig. $9 A b, A d)$. Frequency of fp bursts was not significantly changed in low $\left[\mathrm{Ca}^{2+}\right]_{\mathrm{o}}(133 \pm$ $42 \%$ of control, $n=7, p=0.08$ ) In one slice (P8), showing sharp fp events in the control, lowering $\left[\mathrm{Ca}^{2+}\right]_{\mathrm{o}}$ strongly and reversibly increased events frequency $(\mathrm{FE})$ and duration (percentage of values in $1.6 \mathrm{~mm}\left[\mathrm{Ca}^{2+}\right]_{\mathrm{o}}$; DE: 141\%; PA: 91.5\%, FE: 266\%) (Fig. $9 \mathrm{Ab}$, top trace).

In five of seven tested slices at P11-P13, lowering of $\left[\mathrm{Ca}^{2+}\right]_{\mathrm{o}}$ reversibly modified slow-wave rhythmicity into continuous $\mathrm{fp}$ fluctuations $(\sim 20-40 \mathrm{~Hz})$, going without well distinguishable fp bursts (Fig. 9Ac). In the remaining two slices reduction of $\left[\mathrm{Ca}^{2+}\right]_{\mathrm{o}}$ elicited expansion of fp bursts (DE: $\sim 150 \%$ of control).

To examine whether prolonged intrinsic bursting of immature $\mathrm{mEC}$ neurons is essential for the generation of network periodic activity, we tested the effect of FFA (10-50 $\mu \mathrm{M})$, a blocker of prolonged bursts, on spontaneous fp events at P5-P7. We found that $50 \mu \mathrm{M}$ FFA completely blocked the fp events in all eight tested slices (Fig. 9Ba). In fact, FFA inhibited periodic field activity in a dose-dependent manner. Thus, bath application of $10 \mu \mathrm{M}$ FFA already suppressed the occurrence of fp events up to $50 \%(n=7)$ and $20 \mu \mathrm{M} \mathrm{FFA} \mathrm{up} \mathrm{to} 90 \%(n=7)$. Thus, we used 50 $\mu \mathrm{M}$ to provide the full block in further experiments. At higher concentrations $(100-200 \mu \mathrm{M})$, FFA has several nonspecific effects, including influence on calcium channels and NMDARs (Wang et al., 2006). Since periodic spontaneous network activity critically depends on iGluR-mediated neurotransmission, we investigated a possible influence of $50 \mu \mathrm{M}$ FFA on the excitatory postsynaptic field potential (fEPSP) (supplemental Fig. 5, available at www.jneurosci.org as supplemental material). We found that FFA (bath application for 40-60 min) only slightly affected AMPA/kainate receptor- and NMDAR-mediated components 
of synaptic responses (percentage of the control amplitude; antidromic response: $102 \pm 11 \%, p=0.73$; AMPA/kainate: $122 \pm 8 \%, p=0.004$; NMDA: $90 \pm 4 \%$, $p=0.006, n=5$ ) (for details, see Materials and Methods). In addition, fp events evoked by electrical stimulations were completely blocked by FFA, and a further increase of stimulus intensity (tested up to $40 \mathrm{~V}$ ) causes an enhancement in synaptic responses but was unable to reinduce $\mathrm{fp}$ events $(n=8)$ (supplemental Fig. 5C, available at www.jneurosci.org as supplemental material), suggesting that the effect of FFA on spontaneous fp events was not due to a supression of synaptic transmission.

However, $I_{\text {CAN }}$ might contribute to the depolarization of EC neurons, and thus blockade of $I_{\text {CAN }}$ by FFA can decrease the general level of tonic excitation that is essential for the promotion of the periodic spontaneous network activity. We therefore examined whether FFA could be also efficient after cellular depolarization caused by elevation of $\left[\mathrm{K}^{+}\right]_{\mathrm{o}}$ to $8 \mathrm{~mm}$. Indeed, we found that FFA suppressed periodic spontaneous fp activity to $\sim 90 \%$, even in high $\left[\mathrm{K}^{+}\right]_{\mathrm{o}}(n=10)$ (Fig. $9 \mathrm{Bb}$ ), suggesting that the effect of FFA was not through its action on the tonic depolarization but probably was related to the blockade of prolonged intrinsic bursts. Riluzole [10 $\mu \mathrm{M}(n=6)$, five slices tested in $5.5 \mathrm{mM}$ $\left.\left[\mathrm{K}^{+}\right]_{\mathrm{o}}\right]$ also blocked spontaneous $\mathrm{fp}$ events, though field synaptic response was strongly reduced $(\sim 80 \%)$. Finally, we found that $50 \mu \mathrm{M}$ FFA (bath application for 40-60 min) modulated spontaneous slow-wave network rhythmicity at P11P13 (percentage of control values; DE: $41 \pm 15 \%, p<0.005$; PA: $121 \pm 51 \%, p=$ 0.25 ; FE: $180 \pm 69 \%, p<0.01 ; n=9$ ) (Fig. $9 B c$ ). The above experiments suggest that prolonged intrinsic bursting activity may contribute to the generation of network periodic events in the immature mEC.

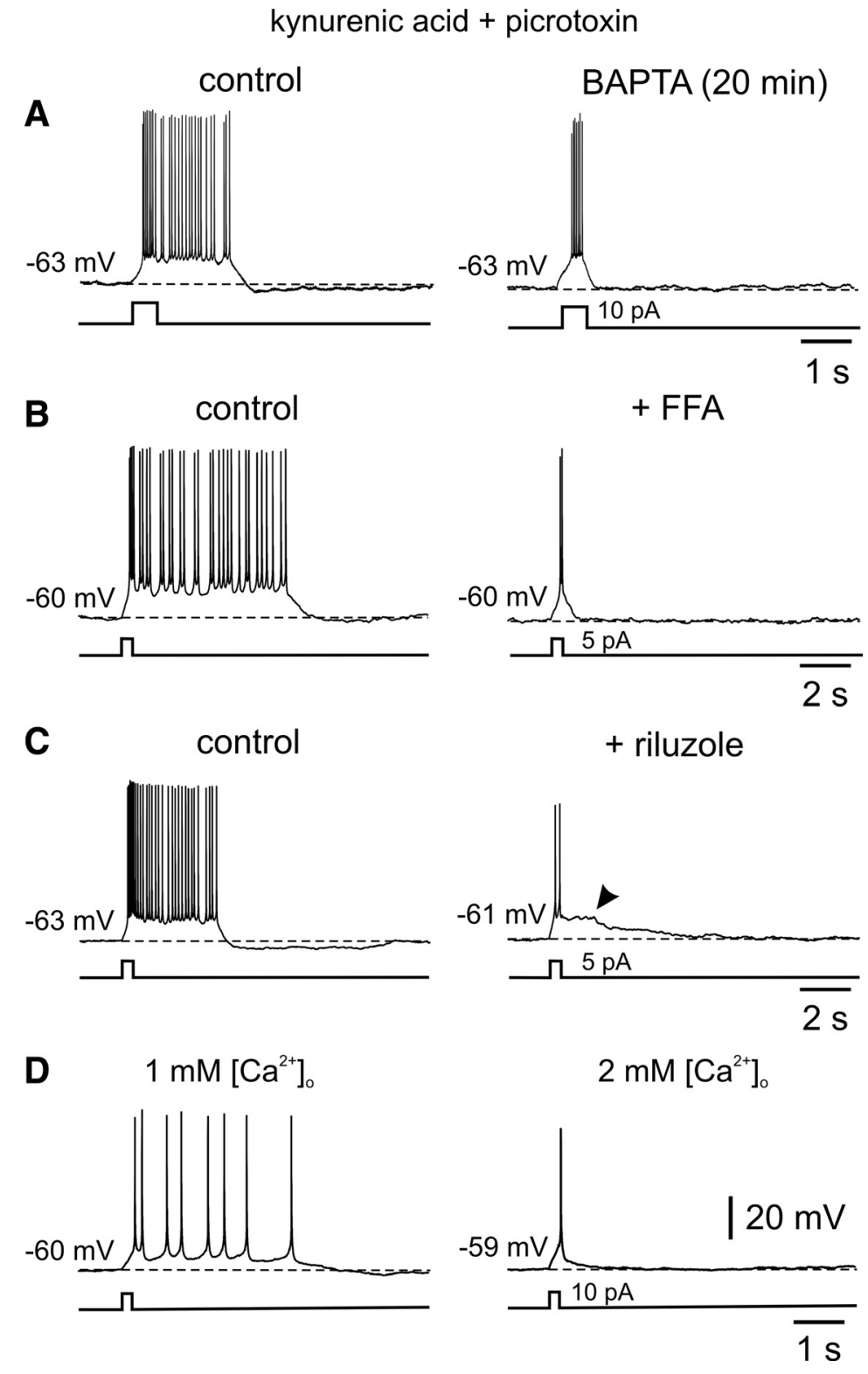

Figure 7. Ionic mechanism of terminated plateau potential in immature mEC LIII neurons. $A, B$, The plateau potential response to current steps is completely blocked by buffering intracellular $\mathrm{Ca}^{2+}$ with $30 \mathrm{~mm}$ BAPTA $(\boldsymbol{A})$ or by bath application of $50 \mu \mathrm{M}$ FFA (B). C, The plateau potential is suppressed by $10 \mu \mathrm{m}$ riluzole (indicated by the arrowhead). Recordings were made in ACSF containing $1 \mathrm{~mm} \mathrm{Ca}^{2+}$.D, Increase of $\left[\mathrm{Ca}^{2+}\right]_{0}$ from 1 to $2 \mathrm{~mm}$ that resulted in a switch from prolonged bursting activity to regular firing is accompanied by the disappearance of the plateau potential. All recordings were obtained in the presence of kynurenic acid and picrotoxin.

\section{Discussion}

In this study, we investigated the early spontaneous fp activity and intrinsic firing pattern of developing mEC LIII principal neurons. We identified three distinct patterns of intrinsic firing behavior of immature neurons: prolonged bursting, short bursting, and regular firing activity. We found that $\left[\mathrm{Ca}^{2+}\right]_{\mathrm{o}}$ modulates intrinsic firing mode at a range of $1-2 \mathrm{~mm}$. We propose that $I_{\mathrm{CAN}}$ and $I_{\mathrm{Nap}}$ underlie prolonged bursts and that $I_{\mathrm{AHP}}$ (BK current) is involved in burst termination. We further suggest that prolonged intrinsic bursting activity may participate in the generation of fp events.

\section{Developmental profile of periodic spontaneous field activity} in the immature mEC

Spontaneous fp activity in rat entorhinal cortical slices is characterized by its weak expression around birth (P1-P4) and periodic fp events at P5-P7 and is followed by slow-wave network rhythmicity. The latter becomes dominant at P11-P13 and during the juvenile period. In general, spontaneous fp activity is markedly increased during the first two postnatal weeks. Interestingly, quite similar activity patterns (spontaneous periodic events and SWOs) were reported in the mEC LIII of adult rodents in vitro (Dickson et al., 2003; Cunningham et al., 2006; Gnatkovsky et al., 2007); however, the underlying mechanisms could be different. Slow-wave activity at P11-P13 possibly represents a pattern observed during sleep and anesthesia (Steriade, 2006). cENOs and cGDPs are synapse-mediated distinct early network patterns, characterized by different spatiotemporal dynamics both in electrical and optical recordings (Allène et al., 2008). We investigated spontaneous network activity in slices by using only fp record- 


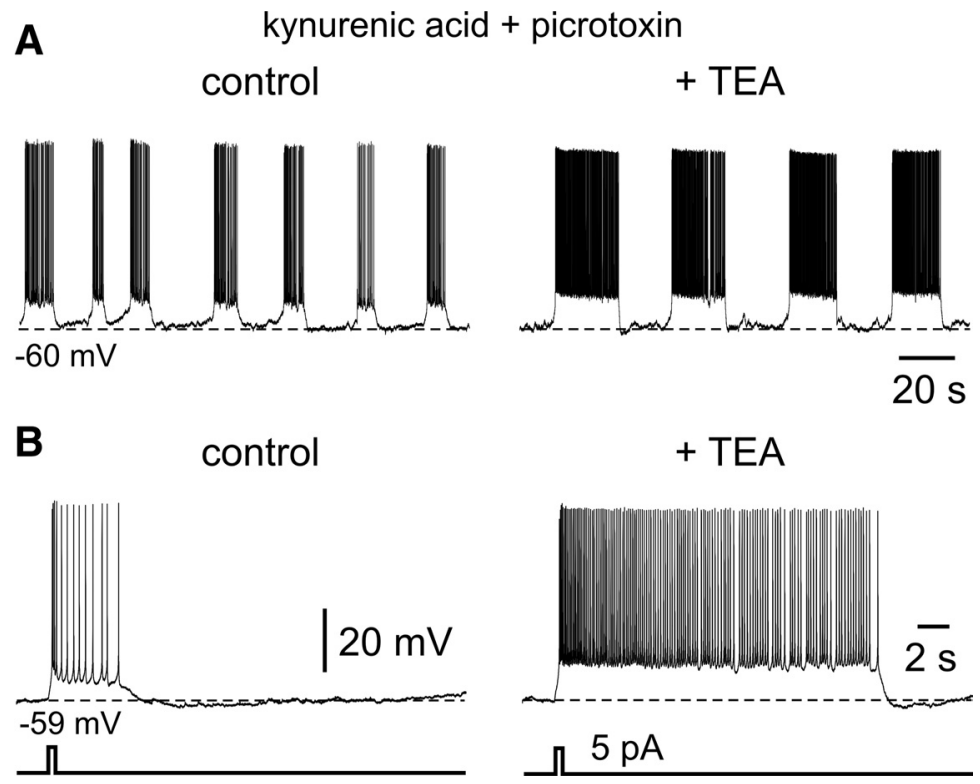

Figure 8. $\mathrm{Ca}^{2+}$-activated $\mathrm{K}^{+}$currents (BK currents) play a role in the termination of prolonged intrinsic bursting activity. $A$, Prolonged bursting activity in control conditions and after the addition of TEA (1 mM). TEA prolongs burst duration and simultaneously increases the firing frequency during bursts. $\boldsymbol{B}$, Duration and firing frequency of the plateau potential triggered by a depolarizing current step are also significantly enhanced in the presence of TEA. All recordings were made in the presence of kynurenic acid and picrotoxin.

ings; thus, it is difficult to compare it to the described patterns precisely. Periodic fp activity in the immature $\mathrm{mEC}$ is mediated by iGluRs, similar to cENOs, and different to cSPAs or other early gap junction synchronized cortical oscillations (Sun and Luhmann, 2007). The duration of fp bursts is also comparable to the duration of cENOs measured by fp recordings $(\sim 3 \mathrm{~s})$. However, in contrast to the somatosensory cortex, in which expression of cENOs peaks around birth (P0-P3) and vanishes when cGDPs dominate the network (P6-P8), fp activity in EC slices is weak at P1-P4, and iGluRs-mediated fp bursts initially appear around P5. Such time differences could reflect the different functions of these two cortical structures. The $\mathrm{mEC}$ is involved in spatial representation and navigation (Moser et al., 2008) that, in comparison with sensory representation, might be less essential at very early postnatal stages. We did not observe a principal pattern corresponding to GABA-driven cGDPs (Allène et al., 2008), and a selective blockade of $\mathrm{GABA}_{\mathrm{A}}$ receptors always elicited paroxysmal field discharges. Thus, iGluR-mediated neurotransmission seems to dominate in the generation of early network activity in the mEC. However, our results do not exclude the presence of GABA-driven activity in the immature mEC, since slow-wave pattern can suppress/hide it.

\section{Ionic mechanisms of prolonged intrinsic bursting activity} Importantly, a fraction of developing mEC LIII neurons spontaneously generate prolonged $\mathrm{Ca}^{2+}$ - and voltage-dependent intrinsic bursting activity. Intrinsic mechanisms for burst generation have been demonstrated in a variety of neurons (Crunelli et al., 2005, Bal and McCormick, 1993, Del Negro et al., 2005), including the juvenile visual cortex (Le Bon-Jego and Yuste, 2007) and hippocampus (Su et al., 2001, Sipilä et al., 2005). Based on the physiological and pharmacological properties of prolonged bursts, we suggest the following cascade of currents underlying the prolonged bursting activity in developing $\mathrm{mEC}$ LIII neurons: (1) slow regenerative depolarization leading to intrinsic bursts is driven by $I_{\text {Nap }}$ and inactivating $\mathrm{Ca}^{2+}$-dependent $\mathrm{K}^{+}$ currents, but not by low-threshold T-type $\mathrm{Ca}^{2+}$ currents; (2) membrane depolarization (and subsequent $\mathrm{Na}^{+}$-dependent spikes) induces activation of high-voltageactivated $\mathrm{Ca}^{2+}$ channels (nifedipinesensitive L-type $\mathrm{Ca}^{2+}$ channel), resulting in $I_{\text {CAN }}$ activation; (3) both $I_{\text {CAN }}$ and $I_{\text {Nap }}$ are involved in the generation of plateau phase of prolonged bursts; (4) the further increase in $\left[\mathrm{Ca}^{2+}\right]_{\mathrm{i}}$ occurring during the spiking activates TEA-sensitive and probably other $\mathrm{Ca}^{2+}$-dependent $\mathrm{K}^{+}$currents that elicit burst termination and the following refractory period. In prolongedbursting neurons, a suprathreshold current step elicits a terminated plateau potential, which is comparable in duration with spontaneous prolonged bursts. Pharmacological properties suggest identical ionic mechanisms for both events, except initiation phase (1).

Our observation that blockade of T-type $\mathrm{Ca}^{2+}$ current did not promote prolonged bursting is in agreement with the fact that in adult LIII pyramidal neurons, subthreshold depolarization to approximately $-53 \mathrm{mV}$ does not evoke intracellular $\mathrm{Ca}^{2+}$-accumulation (Gloveli et al., 1999). In mEC LIII, selective blockade of the $\mathrm{M}$ current by linopirdine or XE991 switches firing pattern from tonic to bursting mode (Yoshida and Alonso, 2007). We do not exclude the possibility that in immature mEC LIII neurons weakness of M current may contribute to prolonged burst firing. Moreover, Kv7/M channel blocker linopirdine has only a minor effect on neonatal, in contrast to juvenile CA3 pyramidal neurons (Safiulina et al., 2008).

\section{Role of prolonged intrinsic bursting in the generation of periodic spontaneous field events}

A central role of intrinsic firing in the generation of network events has been demonstrated in various neuronal structures, including the immature retina (Zheng et al., 2006), and changes in the intrinsic firing properties of individual neurons have important roles in altering circuit behavior (Destexhe and Marder, 2004). Sipilä and colleagues (2005; 2006) have hypothesized that intrinsic bursting of CA3 pyramidal neurons drives and shapes hippocampal GDPs, although GABA- and glutamate-mediated transmissions promote their generation. Our results suggest that prolonged intrinsic bursting of principal neurons may contribute to the generation of periodic spontaneous fp events in the immature mEC. We show that fp events in the mEC occur hippocampus-independently and require selective activation of iGluRs. Both fp events and prolonged firing are inducible by synaptic activation. Elevation of $\left[\mathrm{K}^{+}\right]_{\mathrm{o}}$ as well as lowering $\left[\mathrm{Ca}^{2+}\right]_{\mathrm{o}}$ resulted in an increase in prolonged intrinsic bursting leading to an appearance of fp bursts or to a significant increase of its duration. Finally, FFA (a blocker of prolonged intrinsic bursts) completely prevents spontaneous fp events at P5-P7, without affecting tonic depolarization or synaptic neurotransmission. However, in view of the nonspecificity of FFA, this point needs further investigation. 
A $\quad 1.6 \mathrm{mM}\left[\mathrm{Ca}^{2+}\right]$ 。

a

P5 - P7

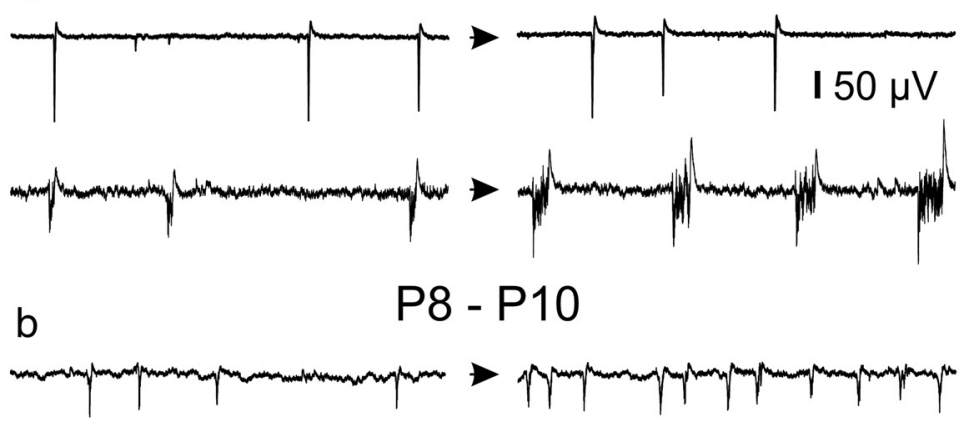

HWw
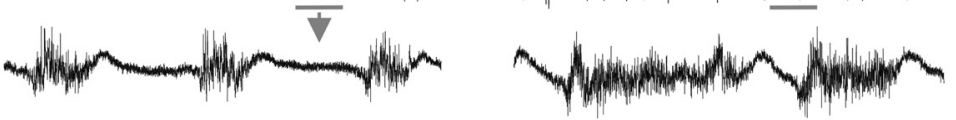

c

P11 - P13

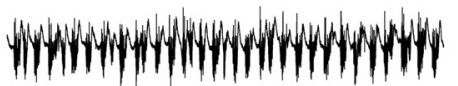
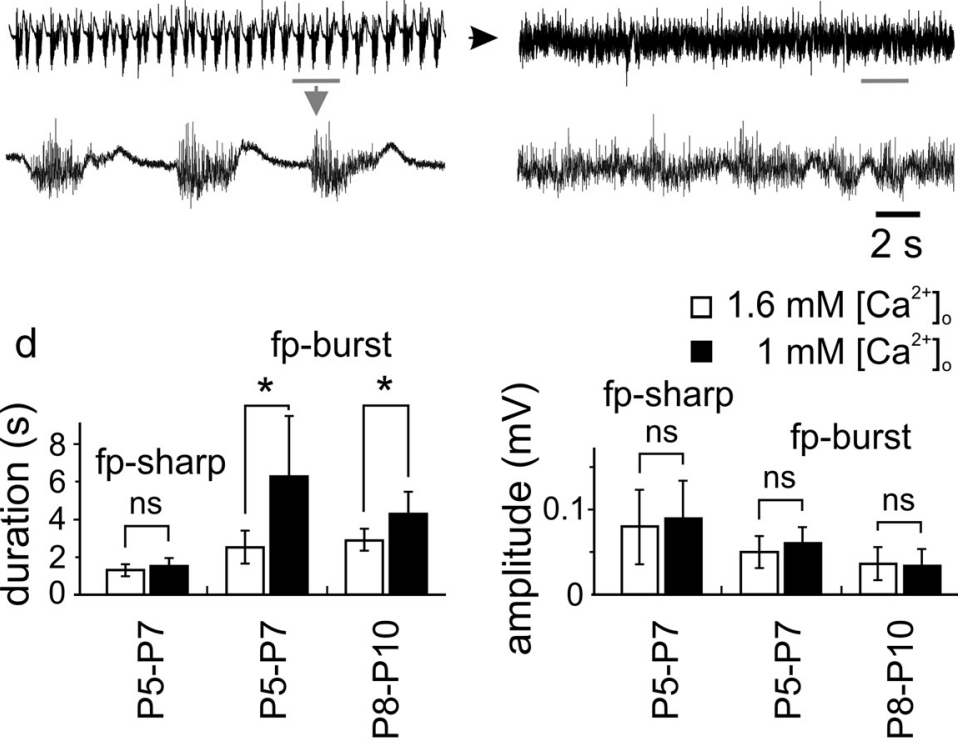

B

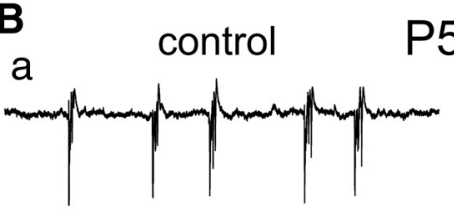

b $8 \mathrm{mM}\left[\mathrm{K}^{+}\right]_{\text {。 }}$

+ FFA
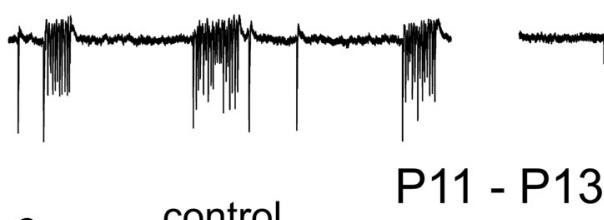

C

$$
\text { control }
$$$$
\text { P11 - P13 }
$$

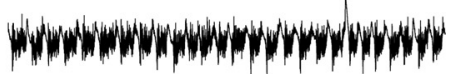

+ FFA
$\left[\mathrm{Ca}^{2+}\right]_{\mathrm{o}}$ dependency and functional implications of prolonged bursting The pattern of intrinsic firing activity of immature mEC LIII neurons displays a significant $\left[\mathrm{Ca}^{2+}\right]_{\mathrm{o}}$ dependence: lowering $\left[\mathrm{Ca}^{2+}\right]_{\mathrm{o}}$ increases, whereas elevating $\left[\mathrm{Ca}^{2+}\right]_{\mathrm{o}}$ decreases the tendency to generate bursts. A similar tendency was described for adult hippocampal CA1 pyramidal neurons (Su et al., 2001). The burst-firing of CA1 neurons is $I_{\mathrm{Nap}^{-}}$ dependent and thus, lowering $\left[\mathrm{Ca}^{2+}\right]_{0}$ to $1 \mathrm{~mm}$ induced intrinsic bursting preferentially by increasing $I_{\mathrm{Nap}}$ [i.e., by shifting voltage dependence of $I_{\text {Nap }}$ activation to more negative potentials (Yue et al., $2005)]$. We suggest that the $\left[\mathrm{Ca}^{2+}\right]_{\mathrm{o}^{-}}$ dependent shift of $I_{\mathrm{Nap}}$-activation in $\mathrm{mEC}$ LIII neurons also plays a central role in the augmentation of prolonged bursts or in the transformation of regular firing to prolonged-bursting mode. Additionally, low $\left[\mathrm{Ca}^{2+}\right]_{\mathrm{o}}$ could influence the balance between depolarizing and hyperpolarizing currents (e.g., $I_{\mathrm{CAN}} / I_{\mathrm{AHP}}$ ) that might be essential for these transformations.

The perforant path (or temporoammonic path) provides direct input from EC LIII to the apical dendritic tuft of hippocampal CA1 pyramidal neurons (Witter and Amaral, 2004). This suggests that neuronal activity of immature mEC LIII neurons contributes to hippocampal development. Thus, a direct excitatory pathway from LIII is critical for the establishment and maintenance of distal dendritic enrichment of a HCN1 channel in CA1 pyramidal neurons (Shin and Chetkovich, 2007). Interestingly, modeling studies have revealed that strong per-

$\leftarrow$

activity in the immature $\mathrm{mEC}$ before and after reduction of $\left[\mathrm{Ca}^{2+}\right]_{0}$ to $1 \mathrm{~mm}$. Aa, At P5-P7, lowering of $\left[\mathrm{Ca}^{2+}\right]_{0}$ does not change sharp $\mathrm{fp}$ events (top); however, it significantly increases the duration of fp bursts (bottom). $\boldsymbol{A} \boldsymbol{b}$, Top, Specimen trace of an fp recording of spontaneous sharp fp events in a $P 8$ slice under control conditions and after reduction of $\left[\mathrm{Ca}^{2+}\right]_{0}$. Note that lowering of $\left[\mathrm{Ca}^{2+}\right]_{0}$ strongly increases event frequency. $\boldsymbol{A} \boldsymbol{b}$, Bottom, Characteristic prolongation of fp bursts at P8-P10 caused by reduction of $\left[\mathrm{Ca}^{2+}\right]_{0}$. Ac, At P11-P13, decreasing $\left[\mathrm{Ca}^{2+}\right]_{0}$ modifies slow-wave rhythmicity into continuous $\mathrm{fp}$ fluctuations. Parts of the traces noted by horizontal bars are shown below in the expanded time scale. $\boldsymbol{A d}$, Bar diagrams representing the mean durations and peak amplitudes of sharp fp events and fp bursts in 1.6 and $1 \mathrm{~mm}\left[\mathrm{Ca}^{2+}\right]_{0}$. Error bars indicate SD. ${ }^{*} p<0.05$. ns, Not significant. $\boldsymbol{B}$, Effect of FFA on spontaneous fp activity at P5-P7 and P11-P13. Ba, Periodic spontaneous $\mathrm{fp}$ events are fully blocked in the presence of $20 \mu \mathrm{m}$ FFA (sample at P7). B $\boldsymbol{b}$, Spontaneous fp activity increases during enhanced tonic excitation following elevation of $\left[\mathrm{K}^{+}\right]_{0}$ and is strongly decreased after adding $50 \mu \mathrm{m}$ FFA (sample trace at P5). $B C$, FFA (50 $\mu \mathrm{M})$ modulates spontaneous slow-wave network rhythmicity at P11-P13.

Figure 9. Effects of lowering $\left[\mathrm{Ca}^{2+}\right]_{0}$ and FFA on periodic spontaneous field activity in the developing mEC. $A$, Spontaneous fp 
forant path activation is required to induce dendritic spikes in the distal apical dendrite that could propagate to the soma of CA1 pyramidal neurons and trigger an action potential (Jarsky et al., 2005), suggesting that distal CA1 dendritic signals propagate more reliably during EC LIII bursts. We detected intrinsic bursting activity only in early postnatal, but not in adult mEC LIII neurons (tested in 2 and $1 \mathrm{~mm}\left[\mathrm{Ca}^{2+}\right]_{\mathrm{o}}$ ). This confirms previous in vitro observations showing that $\mathrm{mEC}$ LIII pyramidal cells of adult rats are regularly spiking neurons that do not discharge bursts of action potentials (Dickson et al., 1997; Gloveli et al., 1997; Yoshida and Alonso, 2007). However, in brain slices of macaque monkeys, it has been shown that $19 \%$ of mEC LIII neurons display intrinsic bursting (Buckmaster et al., 2004) (tested in $2 \mathrm{~mm}\left[\mathrm{Ca}^{2+}\right]_{\mathrm{o}}$ ).

Prolonged intrinsic bursting activity is a feature of developing but not mature rat mEC LIII neurons. In contrast to pacemakerlike neuronal activity described in the juvenile mouse visual cortex (Le Bon-Jego and Yuste, 2007), prolonged intrinsic bursting activity is not observed at the third postnatal week. Importantly, the intrinsic firing pattern is not an invariable permanent attribute of developing mEC LIII neurons. However, our results suggest that neurons which are already able to convert from immature prolonged bursting to the mature regular firing pattern by $2 \mathrm{mM}\left[\mathrm{Ca}^{2+}\right]_{\mathrm{o}}$ are more mature than neurons showing prolonged bursting activity at both $\left[\mathrm{Ca}^{2+}\right]_{\mathrm{o}}$ concentrations. Moreover, the switch to a mature regular firing mode could be due to developmental changes in the $I_{\mathrm{CAN}} / I_{\mathrm{AHP}}$ ratio (our unpublished observations), such as enhancement of $I_{\mathrm{AHP}}$ (Kang et al., 1996) or reduction of $I_{\mathrm{CAN}}$. In mature mEC neurons, $I_{\mathrm{CAN}}$ underlies persistent firing (Klink and Alonso, 1997; Egorov et al., 2002; AlYahya et al., 2003; Fransén et al., 2006). However, $I_{\mathrm{CAN}}$-mediated persistent activity requires activation of muscarinic-cholinergic receptors or mGluRs, and the postnatal increase in neurons endowed with persistent firing properties in mEC was found to parallel the development of the cholinergic system (Reboreda et al., 2007). Thus, the decrease of $I_{\mathrm{CAN}}$ might result from its functional switch from spontaneous $\mathrm{Ca}^{2+}$-dependent activation at an early developmental stage to a muscarinic receptor/ mGluR-mediated activation at a mature stage. To conclude, we suggest that prolonged intrinsic bursting of immature mEC LIII neurons could play an important role in cortical and hippocampal development.

\section{References}

Adelsberger H, Garaschuk O, Konnerth A (2005) Cortical calcium waves in resting newborn mice. Nat Neurosci 8:988-990.

Allène C, Cattani A, Ackman JB, Bonifazi P, Aniksztejn L, Ben-Ari Y, Cossart $\mathrm{R}$ (2008) Sequential generation of two distinct synapse-driven network patterns in developing neocortex. J Neurosci 28:12851-12863.

Al-Yahya E, Hamel E, Kennedy TE, Alonso AA, Egorov AV (2003) Persistent activity in entorhinal cortex neurons induced by muscarinic and metabotropic glutamate receptor activation and its dependence on TRP channels. Soc Neurosci Abstr 377.5.

Anderson WW, Collingridge GL (2001) The LTP program: a data acquisition program for on-line analysis of long-term potentiation and other synaptic events. J Neurosci Methods 108:71-83.

Bal T, McCormick DA (1993) Mechanisms of oscillatory activity in guineapig nucleus reticularis thalami in vitro: a mammalian pacemaker. J Physiol 468:669-691.

Ben-Ari Y (2002) Excitatory actions of gaba during development: the nature of the nurture. Nat Rev Neurosci 3:728-739.

Ben-Ari Y, Cherubini E, Corradetti R, Gaiarsa JL (1989) Giant synaptic potentials in immature rat CA3 hippocampal neurones. J Physiol 416:303-325.

Ben-Ari Y, Gaiarsa JL, Tyzio R, Khazipov R (2007) GABA: a pioneer trans- mitter that excites immature neurons and generates primitive oscillations. Physiol Rev 87:1215-1284.

Blethyn KL, Hughes SW, Tóth TI, Cope DW, Crunelli V (2006) Neuronal basis of the slow $(<1 \mathrm{~Hz})$ oscillation in neurons of the nucleus reticularis thalami in vitro. J Neurosci 26:2474-2486.

Buckmaster PS, Alonso A, Canfield DR, Amaral DG (2004) Dendritic morphology, local circuitry, and intrinsic electrophysiology of principal neurons in the entorhinal cortex of macaque monkeys. J Comp Neurol 470:317-329.

Corlew R, Bosma MM, Moody WJ (2004) Spontaneous, synchronous electrical activity in neonatal mouse cortical neurones. J Physiol 560:377-390.

Crépel V, Aronov D, Jorquera I, Represa A, Ben-Ari Y, Cossart R (2007) A parturition-associated nonsynaptic coherent activity pat tern in the developing hippocampus. Neuron 54:105-120.

Cruikshank SJ, Hopperstad M, Younger M, Connors BW, Spray DC, Srinivas M (2004) Potent block of Cx36 and Cx50 gap junction channels by mefloquine. Proc Natl Acad Sci U S A 101:12364-12369.

Crunelli V, Tóth TI, Cope DW, Blethyn K, Hughes SW (2005) The 'window' T-type calcium current in brain dynamics of different behavioural states. J Physiol 562:121-129.

Cunningham MO, Pervouchine DD, Racca C, Kopell NJ, Davies CH, Jones RS, Traub RD, Whittington MA (2006) Neuronal metabolism governs cortical network response state. Proc Natl Acad Sci U S A 103:5597-5601.

Del Negro CA, Morgado-Valle C, Hayes JA, Mackay DD, Pace RW, Crowder EA, Feldman JL (2005) Sodium and calcium current-mediated pacemaker neurons and respiratory rhythm generation. J Neurosci 25:446-453.

Destexhe A, Marder E (2004) Plasticity in single neuron and circuit computations. Nature 14:789-795.

Dickson CT, Mena AR, Alonso A (1997) Electroresponsiveness of medial entorhinal cortex layer III neurons in vitro. Neuroscience 81:937-950.

Dickson CT, Biella G, de Curtis M (2003) Slow periodic events and their transition to gamma oscillations in the entorhinal cortex of the isolated guinea pig brain. J Neurophysiol 90:39-46.

Dupont E, Hanganu IL, Kilb W, Hirsch S, Luhmann HJ (2006) Rapid developmental switch in the mechanisms driving early cortical columnar networks. Nature 439:79-83.

Egorov AV, Hamam BN, Fransén E, Hasselmo ME, Alonso AA (2002) Graded persistent activity in entorhinal cortex neurons. Nature 420:173-178.

Feller MB (1999) Spontaneous correlated activity in developing neural circuits. Neuron 4:653-656.

Feller MB, Wellis DP, Stellwagen D, Werblin FS, Shatz CJ (1996) Requirement for cholinergic synaptic transmission in the propagation of spontaneous retinal waves. Science 272:1182-1187.

Fransén E, Tahvildari B, Egorov AV, Hasselmo ME, Alonso AA (2006) Mechanism of graded persistent cellular activity in entorhinal cortex layer V neurons. Neuron 49:735-746.

Garaschuk O, Linn J, Eilers J, Konnerth A (2000) Large-scale oscillatory calcium waves in the immature cortex. Nat Neurosci 3:452-459.

Gloveli T, Schmitz D, Empson RM, Dugladze T, Heinemann U (1997) Morphological and electrophysiological characterization of layer III cells of the medial entorhinal cortex of the rat. Neuroscience 77:629-648.

Gloveli T, Egorov AV, Schmitz D, Heinemann U, Müller W (1999) Carbachol-induced changes in excitability and $[\mathrm{Ca} 2+] \mathrm{i}$ signalling in projection cells of medial entorhinal cortex layers II and III. Eur J Neurosci 11:3626-3636.

Gnatkovsky V, Wendling F, de Curtis M (2007) Cellular correlates of spontaneous periodic events in the medial entorhinal cortex of the in vitro isolated guinea pig brain. Eur J Neurosci 26:302-311.

Hanganu IL, Ben-Ari Y, Khazipov R (2006) Retinal waves trigger spindle bursts in the neonatal rat visual cortex. J Neurosci 26:6728-6736.

Jarsky T, Roxin A, Kath WL, Spruston N (2005) Conditional dendritic spike propagation following distal synaptic activation of hippocampal CA1 pyramidal neurons. Nat Neurosci 12:1667-1676.

Kandler K, Katz LC (1998) Coordination of neuronal activity in developing visual cortex by gap junction-mediated biochemical communication. J Neurosci 18:1419-1427.

Kang J, Huguenard JR, Prince DA (1996) Development of BK channels in neocortical pyramidal neurons. J Neurophysiol 76:188-198.

Khazipov R, Luhmann HJ (2006) Early patterns of electrical activity in the 
developing cerebral cortex of humans and rodents. Trends Neurosci 29:414-418.

Khazipov R, Sirota A, Leinekugel X, Holmes GL, Ben-Ari Y, Buzsáki G (2004) Early motor activity drives spindle bursts in the developing somatosensory cortex. Nature 432:758-761.

Klink R, Alonso A (1997) Ionic mechanisms of muscarinic depolarization in entorhinal cortex layer II neurons. J Neurophysiol 77:1829-1843.

Le Bon-Jego M, Yuste R (2007) Persistently active, pacemaker-like neurons in neocortex. Front Neurosci 1:123-129.

Leinekugel X, Medina I, Khalilov I, Ben-Ari Y, Khazipov R (1997) Ca2+ oscillations mediated by the synergistic excitatory action of GABAA and NMDA receptors in the neonatal hippocampus. Neuron 18:243-255.

Moser EI, Kropff E, Moser MB (2008) Place cells, grid cells, and the brain's spatial representation system. Annu Rev Neurosci 31:69-89.

O’Donovan MJ (1999) The origin of spontaneous activity in developing networks of the vertebrate nervous system. Curr Opin Neurobiol 9:94-104.

Partridge LD, Valenzuela CF (2000) Block of hippocampal CAN channels by flufenamate. Brain Res 867:143-148.

Reboreda A, Raouf R, Alonso A, Séguéla P (2007) Development of cholinergic modulation and graded persistent activity in layer $\mathrm{V}$ of medial entorhinal cortex. J Neurophysiol 97:3937-3947.

Rheims S, Minlebaev M, Ivanov A, Represa A, Khazipov R, Holmes GL, Ben-Ari Y, Zilberter Y (2008) Excitatory GABA in rodent developing neocortex in vitro. J Neurophysiol 100:609-619.

Safiulina VF, Zacchi P, Taglialatela M, Yaari Y, Cherubini E (2008) Low expression of Kv7/M channels facilitates intrinsic and network bursting in the developing rat hippocampus. J Physiol 586:5437-5453.

Shin M, Chetkovich DM (2007) Activity-dependent regulation of h channel distribution in hippocampal CA1 pyramidal neurons. J Biol Chem 282:33168-33180.

Sipilä ST, Huttu K, Soltesz I, Voipio J, Kaila K (2005) Depolarizing GABA acts on intrinsically bursting pyramidal neurons to drive giant depolarizing potentials in the immature hippocampus. J Neurosci 25:5280-5289.

Sipilä ST, Huttu K, Voipio J, Kaila K (2006) Intrinsic bursting of immature CA3 pyramidal neurons and consequent giant depolarizing potentials are driven by a persistent $\mathrm{Na}+$ current and terminated by a slow $\mathrm{Ca} 2+-$ activated K+ current. Eur J Neurosci 23:2330-2338.
Squire LR, Stark CE, Clark RE (2004) The medial temporal lobe. Annu Rev Neurosci 27:279-306.

Steriade M (2006) Grouping of brain rhythms in corticothalamic systems. Neuroscience 137:1087-1106.

Su H, Alroy G, Kirson ED, Yaari Y (2001) Extracellular calcium modulates persistent sodium current-dependent burst-firing in hippocampal pyramidal neurons. J Neurosci 21:4173-4182.

Sun JJ, Luhmann HJ (2007) Spatio-temporal dynamics of oscillatory network activity in the neonatal mouse cerebral cortex. Eur J Neurosci 26:1995-2004.

Tahvildari B, Alonso AA, Bourque CW (2008) Ionic basis of ON and OFF persistent activity in layer III lateral entorhinal cortical principal neurons. J Neurophysiol 99:2006-2011.

Urbani A, Belluzzi O (2000) Riluzole inhibits the persistent sodium current in mammalian CNS neurons. Eur J Neurosci 12:3567-3574.

van Strien NM, Cappaert NL, Witter MP (2009) The anatomy of memory: an interactive overview of the parahippocampal-hippocampal network. Nat Rev Neurosci 10:272-282.

Wang D, Grillner S, Wallén P (2006) Effects of flufenamic acid on fictive locomotion, plateau potentials, calcium channels and NMDA receptors in the lamprey spinal cord. Neuropharmacology 51:1038-1046.

Wells JE, Porter JT, Agmon A (2000) GABAergic inhibition suppresses paroxysmal network activity in the neonatal rodent hippocampus and neocortex. J Neurosci 20:8822-8830.

Witter MP, Amaral DG (2004) Hippocampal formation. In: The rat nervous system, Ed 3 (Paxinos GT, ed), pp 635-704. San Diego: Academic.

Yoshida M, Alonso A (2007) Cell-type specific modulation of intrinsic firing properties and subthreshold membrane oscillations by the $\mathrm{M}(\mathrm{Kv} 7)$-current in neurons of the entorhinal cortex. J Neurophysiol 98:2779-2794.

Yoshida M, Fransén E, Hasselmo ME (2008) mGluR-dependent persistent firing in entorhinal cortex layer III neurons. Eur J Neurosci 6:1116-1126.

Yue C, Remy S, Su H, Beck H, Yaari Y (2005) Proximal persistent $\mathrm{Na}^{+}$ channels drive spike afterdepolarizations and associated bursting in adult CA1 pyramidal cells. J Neurosci 25:9704-9720.

Yuste R, Peinado A, Katz LC (1992) Neuronal domains in developing neocortex. Science 257:665-669.

Zheng J, Lee S, Zhou ZJ (2006) A transient network of intrinsically bursting starburst cells underlies the generation of retinal waves. Nat Neurosci 9:363-371. 